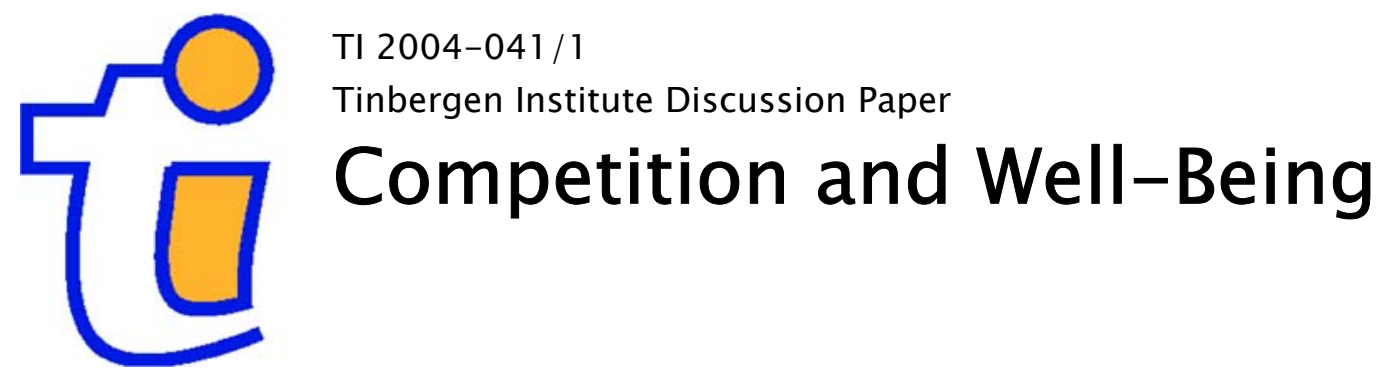

Jordi Brandts ${ }^{\prime}$

Arno Ried/2

Frans van Winden²

I Institut d'Anàlisi Econòmica (CSIC), Barcelona,

2 CREED, Faculty of EConomics and Econometrics, Universiteit van Amsterdam, and Tinbergen Institute. 


\section{Tinbergen Institute}

The Tinbergen Institute is the institute for economic research of the Erasmus Universiteit Rotterdam, Universiteit van Amsterdam, and Vrije Universiteit Amsterdam.

Tinbergen Institute Amsterdam

Roetersstraat 31

1018 WB Amsterdam

The Netherlands

Tel.: $\quad+31(0) 205513500$

Fax: $\quad+31(0) 205513555$

Tinbergen Institute Rotterdam

Burg. Oudlaan 50

3062 PA Rotterdam

The Netherlands

Tel.: $\quad+31(0) 104088900$

Fax: $\quad+31(0) 104089031$

Please send questions and/or remarks of nonscientific nature to driessen@tinbergen.nl.

Most TI discussion papers can be downloaded at http://www.tinbergen.nl. 


\title{
Competition and Well-Being*
}

\author{
Jordi Brandts ${ }^{\dagger}$ \\ Arno Riedl ${ }^{\ddagger}$
}

Frans van Winden ${ }^{\S}$

April 2004

\begin{abstract}
We study the effects of competition in a context in which people's actions can not be contractually fixed. We find that in such an environment the very presence of competition does neither increase efficiency nor does it yield any payoff gains for the short side of the market. We also find that competition has a strong negative impact on social well-being, the disposition towards others, and individually experienced well-being, the emotional state, of those on the long side of the market. We conjecture that this limits the possibilities of satisfactory interaction in the future and, hence, has negative implications for efficiency in the longer-run.
\end{abstract}

JEL Classification Numbers: A13, C92, D30, J50, M50

Keywords: competition, happiness, well-being, laboratory experiment, emotions, market interaction

*The authors thank Armin Falk, Ernst Fehr, Christiane Schwieren, Alaž Ule and the participants of seminars and conferences in Amsterdam, Barcelona, Erfurt, and Zürich for valuable comments, David Rodriguez for excellent research assistance, Karin Breen for the translation of the experimental instructions and Jos Theelen for writing the software for the experiment. Financial support by the European Union through the TMR research network ENDEAR (FMRX-CT98-0238) is gratefully acknowledged.

${ }^{\dagger}$ Institut d'Anàlisi Econòmica (CSIC), Campus UAB, Bellaterra, Barcelona, Spain.

¥Tinbergen Institute and University of Amsterdam, CREED, Faculty of Economics and Econometrics, Roetersstraat 11, NL-1018 WB Amsterdam, The Netherlands, e-mail: a.m.riedl@uva.nl

$\S$ Tinbergen Institute and University of Amsterdam, CREED, Faculty of Economics and Econometrics, Roetersstraat 11, NL-1018 WB Amsterdam, The Netherlands, e-mail: f.a.a.m.vanwinden@uva.nl 


\section{Introduction}

There is a strong consensus in mainstream economics that competition is the key ingredient for spurring efficiency and economic growth. The title of a recent piece on competition in the Economist's Economics Focus puts it in a nutshell: "Competition is all" (December $6^{\text {th }}, 2003$, p. 74). Economists have extensively studied many aspects of the effects of competition for different contexts, as for markets for labor, financial capital, natural resources or commodities. Stigler (1987) points out a crucial feature of competition. In his words: "Competition is a rivalry between individuals (or groups or nations), and it arises whenever two or more parties strive for something that all cannot obtain" (p. 531). In the standard view, it is the very fact that several parties are rivals in a market which has beneficial consequences for the allocation of resources.

In this paper we use experiments to study some potentially important limitations and drawbacks of the rivalry implied by competition. More specifically, we focus on two dimensions of the effects of competition. The first pertains to the fact that competitive forces work out differently depending on the nature of what is transacted in the market. In studying the effects of competition on efficiency, economic analysis has focused mostly on environments in which the features of the traded goods and services can be perfectly pre-specified and controlled. Much less attention has been paid to the impact competition may have in markets in which contracting is incomplete. When complete contracting is not possible the validity of more standard economic analysis may be considerably limited. Fehr, Kirchsteiger and Riedl $(1993,1998)$ study behavior in experimental gift-exchange markets and find strong deviations from the conventional prediction. Other experimental studies of markets with incomplete contracts have confirmed this insight (Hannan, Kagel, and Moser, 2002; Brandts and Charness, 2004). In this paper we specifically investigate whether in markets of this type efficiency is fostered by competition.

The second dimension of the effects of competition we study is its impact on social and subjective well-being. By social well-being we mean people's disposition or attitude towards others, that is, their inclination to hurt or help others. By subjective wellbeing we refer to a global measure of the hedonic state experienced by an individual, as well as to the intensity of experienced individual positive and negative emotions. Both, subjective well-being as well as the disposition towards others may be affected 
by competitive interaction. The rivalry that competition implies may not be costless neither in terms of personal feelings nor in terms of social relations.

Such effects have not received much attention in economics, but need to be studied if one wants to get a complete picture of the impact of competition on economic and social life. Bowles (1998) discusses in detail how different kinds of institutions may affect values, tastes and personalities. One of the several issues he discusses is closely related to the concern about the effect that rivalry may have on well-being. He states: “(..) there are significant differences in the personality effects on participants in markets which clear in equilibrium and those which do not, and in those markets which do not clear, for people on the short side of the market (whose advantageous positions may allow them to make take it or leave it offers) and those on the long side of the market, some of which are simply excluded from the exchange process, while others fear losing the transactions they have secured." (Bowles, 1998, p. 78) The long side of the market is where rivalry takes place.

In our view there are several reasons why it is important to investigate the relationship between competition and well-being. We briefly discuss some of them, distinguishing between direct and derived consequences of rivalry. First, well-being and happiness are undoubtedly central goals of human life. This by itself should be a sufficient reason for studying their relation to different economic institutions. Kahneman, Diener and Schwartz (1999) contains a wealth of information about research on well-being and Frey and Stutzer (2002) provide a recent overview of happiness research and its relation to economics. The question is whether and how people are affected by the kind of environment they are immersed in. This concern for how the environment affects people is also related to issues of procedural fairness. The degree of rivalry can be viewed as one aspect of the procedure under which interaction takes place. By now there is a considerable body of research that supports the premise that satisfaction with process and procedures is an important ingredient of human motivation. ${ }^{1}$

\footnotetext{
${ }^{1}$ Kahneman, Knetsch and Thaler (1986), Barret-Howard and Tyler (1986), and Bies, Tripp and Neale (1993) find that procedural information influences judgments of market exploitation. Charness and Levine (2000) find that perceived fairness of a layoff is highly dependent on the manner in which the layoff is implemented. Bolton, Brandts and Ockenfels (2001) show that different random procedures affect choice behavior. Frey, Benz and Stutzer (2002) outline a concept of procedural utility and suggest how it can be fruitfully integrated into economics. For a summary of some of this literature see Lind and Tyler (1988).
} 
Second, the derived consequences of the presence of competition go beyond the motivational effects and are especially important from a purely economic viewpoint. Interacting under competition may change people's disposition towards others and, in particular, towards those individuals they have encountered in the interaction (and may meet again in the future). This in turn may feed back to individuals' behavior in market places with possibly adverse effects on efficiency. If the interplay between psychological and allocative effects turned out to be significant, it would challenge the conventional view that people's motivation and the economic environment are independent from each other and would affect the very basis of how economists think about competitive interaction.

Our experiment is designed in a way that makes it possible to control for the effects of competition as such. More specifically, we compare subjects' behavior in an experimental condition in which there is competition with behavior in another condition where competition is absent, while holding all the other aspects of the economic environment constant. In our design competition appears in such a way that it is always clear who is on the long and who on the short side of the market. It is completely transparent whether one is interacting under rivalry or not. Another innovative aspect of our design is that we collect data about people's social well-being as well as about their subjective well-being. We do this for both experimental conditions. This allows us to compare subjects' disposition towards others as well as their experienced individual well-being between the two conditions in a controlled way. For the case of competition we can also distinguish between well-being on the short and on the long side of the market. We also study how social and subjective well-being in the different conditions is related to interaction success and monetary earnings in the market place.

We find that in our experimental representation of an environment with incomplete contracting and market imbalance the very presence of competition does not show up as a positive force. Competition does not lead to an increase of material efficiency and does not yield any payoff gains to the short side of the market. We also find that competition has an adverse impact on the disposition towards others of those on the long side of the market. In addition, it leads to lower subjective well-being for participants on the long side of the market, compared to those on the short side and to those not subject to competition. 
Regression analysis shows that market participation affects people's disposition towards others differently, depending on their position in terms of competition. Generally, the disposition of agents on the long side of the market towards those on the short side of the market deteriorates, independently of the interaction success. Specifically, agents who are often excluded from trade show little sensitivity in their disposition towards others with respect to interaction success. It seems that they are discouraged by the exclusion and that the rare events where they are not are insufficient to overcome this effect. We also study whether differences in subjective well-being can be attributed to differences in earnings from the interaction phase. What we find is that earnings alone are not sufficient to explain these differences, but that the role taken in the market place seems to be important, too. In summary, in our data competition does not have positive consequences for material efficiency and has mostly adverse effects on agents' social and individual well-being.

The rest of the paper is organized as follows. In Section 2 we present in detail our experimental design and procedures. In Section 3 we present and discuss our results and Section 4 contains some closing comments.

\section{Design and Procedures}

In our design competition takes place in a stylized representation of a situation with incomplete contracting and repeated interaction between two fixed sides of a relationship. Ongoing relationships, which are characteristic for many if not most market and organizational environments, are the natural context in which to study the issues at hand. Such an environment opens the possibility for psychological effects of competition to accumulate over time. ${ }^{2}$

Our experimental set-up consists of two treatments each of which has three parts. Part 2 is a finitely repeated social dilemma game played by a fixed group of subjects. In parts 1 and 3 subjects make decisions in the circle-test, a task designed to elicit people's disposition towards others. At the end of part 2, subjects' experienced feelings and emotions are measured with the help of a computerized self-assessment questionnaire. Table 1 depicts the sequence of events. We now present each of these parts in detail.

\footnotetext{
${ }^{2}$ Lawler, Yoon, Baker and Large (1995) state that frequent exchange creates emotional ties between the parties involved.
} 
Table 1: Sequence of events

\begin{tabular}{|c|c|c|}
\hline 0. & \multicolumn{2}{|c|}{ General information $\rightarrow$ experiment consists of three parts } \\
\hline & \multicolumn{2}{|l|}{ PART 1} \\
\hline 1. & \multicolumn{2}{|c|}{ Instructions for part 1 only } \\
\hline 2. & \multicolumn{2}{|c|}{ Circle test concerning random stranger } \\
\hline & \multicolumn{2}{|l|}{ PART 2} \\
\hline \multirow[t]{2}{*}{3.} & \multicolumn{2}{|c|}{ Instructions for part 2 only } \\
\hline & in $\mathrm{NCC}$ & in $\mathrm{CC}$ \\
\hline 4. & Incomplete contract game in triad & Incomplete contract game in dyad \\
\hline 5. & \multicolumn{2}{|c|}{ Measurement of global subjective well-being } \\
\hline 6. & \multicolumn{2}{|c|}{ Measurement of specific emotions } \\
\hline & \multicolumn{2}{|l|}{ PART 3} \\
\hline \multirow[t]{2}{*}{7.} & \multicolumn{2}{|c|}{ Instructions for part 3 only } \\
\hline & in $\mathrm{NCC}$ & in $\mathrm{CC}$ \\
\hline \multirow[t]{2}{*}{8.} & Circle test concerning & Circle test concerning \\
\hline & partner and random stranger & both interaction partners \\
\hline
\end{tabular}

The two treatments (conditions) differ mostly with respect to the interactive game played in part 2. In the No Competition Condition (hereafter NCC) the repeated game in part 2 is played in a dyad, a pair of fixed partners, labeled A and B. In contrast, in the Competition Condition (hereafter CC), the game involves a triad of fixed players with fixed roles: A, B and C. ${ }^{3}$ In both, the NCC and the CC, we use the partner design. Since, trading often involves repeated interactions among the same group of agents, this setting is the more realistic one given our research question.

In both the NCC and the CC the number of rounds is 30 . In each round of the game in the $\mathrm{CC}$ the subject in the role of $\mathrm{A}$ has to choose to play either with $\mathrm{B}$ or with C. Since player A can only choose one of the other two players the situation of players with roles $\mathrm{B}$ and $\mathrm{C}$ is one of rivalry in the sense mentioned in the Introduction. Note that, compared to previous experimental work on markets with incomplete contracts, the ratio of market imbalance of $2: 1$ implies a rather high degree of rivalry.

The stage game of the repeated social dilemma game implemented in part 2 is shown in Figure 1. The representation corresponds directly to the NCC condition, where the game is played by two fixed partners, A and B. In each round the two

\footnotetext{
${ }^{3}$ A related game is studied in Davis and Holt (1994).
} 


\begin{tabular}{c|c|c|}
\multicolumn{1}{c}{} & \multicolumn{1}{c}{0} & 10 \\
\cline { 2 - 3 } 0 & 160,160 & 410,40 \\
\cline { 2 - 3 } 10 & 40,410 & 290,290 \\
\cline { 2 - 3 } & &
\end{tabular}

In CC the player not chosen receives 90 .

Figure 1: The stage game

players simultaneously choose between the numbers 0 and 10 . These choices might be interpreted as wage and effort choices in a gift-exchange framework, as quality and price choices in markets of experience goods, and also as a choice between no and full contribution to a public good. Below, we refer to the choices as (rates of) contribution. The CC condition involves one more choice for one of the players. In each round of the CC, player A also chooses between two partners, B and C. Player A and the chosen partner then play the above game while the not chosen player obtains a fixed payment of 90 points. ${ }^{4}$ At the outset the $\mathrm{B}$ and $\mathrm{C}$ players are identical. We chose this route in order to isolate the rivalry feature of competition in its purest form. We wish to stress here that in this paper we do not study other potentially important features of competition like how it contributes to select alternatives that are better ex-ante as, for instance, technically more efficient ones.

The fact that both $\mathrm{A}$ and the chosen partner can freely choose their action in a round represents an incompleteness or absence of contracting on both sides of the business relation. We consider this to be more interesting than the case of one-sided incompleteness in which one side's responsibilities are completely fixed. It also makes the players symmetric with respect to the contribution choice. This is a desirable feature because we want to isolate the effect of competition from other possible influences. This is also the reason why the stage game is symmetric with respect to the payoffs. These symmetries will make it easy to compare behavior and earnings across different conditions and player types. If the earnings and contribution possibilities of the A player

\footnotetext{
${ }^{4}$ Note that the outside payoff is dominated by the payoffs that a B or C player can obtain if he is chosen by $\mathrm{A}$ and chooses 0 . However, the outside payoff is higher than what one gets if one chooses 10 and the A player 0 . In terms of a business relation the situation can be characterized as one in which for firms $\mathrm{B}$ and $\mathrm{C}$ it is worse to contribute to the relation and being taken advantage of than no to get the contract with A at all.
} 
in a round were different from those of the B/C players, it would be less straightforward how the actions of the two types of players and the influence of competition on these actions should be compared.

In the experiments, subjects in the role of $\mathrm{B}$ and $\mathrm{C}$ indicated their choice before they knew whether they had been chosen by A. ${ }^{5}$ A possible variant of this procedure would have been to have A select a partner before the simultaneous play of the stage game. We did not choose this alternative because the pure fact of (the knowledge of) being chosen could have influenced behavior of the B/C players (see, e.g., Brandts, Güth, and Stiehler, 2002). This is a surely important effect but is separate from the issue we are interested in here. Our procedure also yields a more complete picture of behavior and allows us to compare the behavior of matched and unmatched players. Subjects' information depended on the role they were in: In each round, player A was only informed about the choice of the selected player and the $\mathrm{B}$ or $\mathrm{C}$ player were only informed of A's choice if he had been selected. In our view, this information structure is a natural one since in business relations the terms of contract are also typically not revealed to third parties.

In our design the presence or absence of competition is an exogenously given feature to facilitate the separation of the effects of competition. The fact that there is only one player on the short side of the market is an additional advantage of our environment, for the following reason. At all times, it is transparent to all three players in a triad whether $\mathrm{B}$ or $\mathrm{C}$ is unmatched. If after a period of interaction an A player switches away from, say, the B player then the latter player will be unmatched with certainty in the next round. ${ }^{6}$ If there were more than two players on the long side, then the issue would arise whether to inform unmatched players about which of the players had been matched. This information could have an influence on behavior, a possibility we want to avoid.

In our setting the advantage of the A player is obvious. Players B and C lack any direct control about who is chosen. Actually, they can be seen as being at A's mercy, since they do not have a proper refusal possibility. Examples of such situations are the competition between workers for being selected by a superior for a promotion or

\footnotetext{
${ }^{5}$ Our method is akin to the strategy-elicitation method that goes back to Selten (1967).

${ }^{6}$ For the $\mathrm{CC}$ the whole situation evokes the notion of unemployment being used as a disciplining device; see Shapiro and Stiglitz (1984).
} 
cases of procurement where several firms compete offering similar inputs. One might also think of situations in smaller towns or at the workplace, where turning down a work-related or business proposal is socially very difficult. Recall, that in our setting the chosen player on the long side of the market can guarantee himself a payoff higher than the outside option payoff. In this sense, it is always better to trade than not to trade.

The game-theoretic predictions based on the standard assumption of narrow material self-interest differ across the two treatments. Since the stage game of the NCC has the structure of a prisoners' dilemma game both players choose 0 in the unique Nash equilibrium. Consequently, the repeated game has also only one Nash equilibrium, which is subgame-perfect: both players choose 0 in each round.

For the CC things are different. The stage-game now has two Nash equilibria in pure strategies in which all three players involved choose action 0 . The only difference between them is whether A chooses B or C as partner. Importantly, however, the two equilibria are not payoff-equivalent. As a consequence, the repeated CC game also has multiple Nash equilibria and some of them are subgame-perfect. The most obvious subgame-perfect equilibrium involves all three players choosing the non-cooperative choice in every round. However, there are also numerous other subgame-perfect equilibria involving different levels of stable relations between player A and his partners and different degrees of gains from cooperation for players. ${ }^{7}$

All of these equilibria involve all three players choosing the non-cooperative action 0 in the last two rounds. To see this, observe that if, say, B is chosen in the last round he will earn 160, because all players choose the non-cooperative action in that round, implying a gain of 70 relative to the exclusion payoff of 90 . This loss of 70 is smaller than the gain from a deviation in the previous round, $410-290=120$. Considering the

\footnotetext{
${ }^{7}$ One set of equilibria involves one of the players on the long side, say C, always defecting and $\mathrm{A}$ choosing $\mathrm{B}$ as a partner. In the first $k_{1}$ rounds $\mathrm{A}$ and $\mathrm{B}$ both cooperate, in the second $k_{2}$ rounds $\mathrm{A}$ defects and $\mathrm{B}$ cooperates and in final $k_{3}$ rounds both $\mathrm{A}$ and $\mathrm{B}$ defect, where $k_{1}<k_{2}<k_{3}$. In case of a deviation by A, B changes to always defecting and in case of a deviation by $\mathrm{B}, \mathrm{A}$ switches to choosing $\mathrm{C}$ as partner and defects in all subsequent rounds. (We are grateful to Aljaž Ule for providing us with this example.) The punishment corresponding to switching to the other player after defection is credible. Indeed, it prescribes Nash behavior in a subgame induced by a deviation. This kind of analysis is akin to the one suggested by Friedman (1985), Frayssé and Moreau (1985) and Benoit and Krishna (1985).
} 
last two rounds, however, it is clear that the deviation gain of 120 can not compensate for twice foregoing earnings of 70 .

One of the Nash equilibria involves A choosing, say, B, and the cooperative action 10 (except for the last two rounds) whenever B has chosen 10 in the previous round and switching to $\mathrm{C}$ for all remaining rounds if $\mathrm{B}$ chooses action 0 in a round. For player $\mathrm{B}$ it prescribes cooperation in all rounds except the two last ones and for $\mathrm{C}$, the not chosen player, it prescribes the non-cooperative action in all rounds. In this equilibrium, and in the analogous one where A's partnership is with C, A and the chosen partner obtain large gains from cooperation, which in the NCC are not possible in equilibrium. What we wish to highlight here is that there are Nash equilibria, and also subgame perfect ones, that imply considerable cooperation in the $\mathrm{CC}$, in contrast to the NCC. Hence, from the point of view of standard game theory one can expect more cooperation, and hence efficiency gains, in the CC than in the NCC and (at least) the A player earning more in the CC than players in the NCC. Thus, as one would intuitively expect competition turns out to be a potentially positive force, in theory. ${ }^{8}$

Social or other-regarding preferences can easily lead to substantial cooperation in both our conditions. For instance, with the type of distributional preferences posited by Fehr, Kirchsteiger and Riedl (1998), Fehr and Schmidt (1999) or Bolton and Ockenfels (2000) both our stage games can have an equilibrium without cooperation, but also have equilibria in which some subjects cooperate while others defect. ${ }^{9}$ The possibility of cooperation in the repeated versions of the NCC game follows straightforwardly. In the repeated CC game the pattern of cooperation depends on whether players only care

\footnotetext{
${ }^{8}$ The discrepancies in the predictions for the two conditions can be compared to those for an analogous pair of situations with a fixed surplus to be divided. The Nash demand game can, due to its symmetry, be seen as the fixed surplus game parallel to the NCC stage game. Although, any division of the surplus is a Nash equilibrium in the demand game, the equal split seems to be a reasonable prediction, and this is what was found in the experiments reported in Nydegger and Owen (1975). The same situation involving two buyers is an auction with secret reserve price where the only Nash equilibrium implies the whole surplus going to the seller. Here competition clearly favors the short side of the market. Güth, Marchand and Rulliere (forthcoming) present experimental evidence from an ultimatum game with responder competition in which the proposer actually obtains almost all the surplus. Roth et al. (1991) find similar results in a Bertrand-type auction.

${ }^{9}$ Other models of social preferences like Dufwenberg and Kirchsteiger (2004), Falk and Fischbacher (1998) and Charness and Rabin (2002) predict similar patterns.
} 
about the distribution of payoffs between themselves and their partners, or whether they also take into account the unmatched player. In the first case, equilibrium cooperation could involve a stable relation between player A and one of the other two, whereas in the case in which third party payoffs are also relevant some degree of switching between the two players would be involved. ${ }^{10}$

The second building block of our design is the measurement of subjective well-being. At the end of part 2, that is after the last round of the interactive game and without knowing beforehand, subjects had to respond to a computerized questionnaire designed to elicit participants subjective well-being. They were asked to rate themselves with respect to a global subjective well-being indicator as well as with respect to thirteen specific emotions. ${ }^{11}$ The questionnaire used has previously successfully been applied by Bosman and van Winden (2002). We explain the global measure of subjective wellbeing and the emotions questionnaire in detail when we present the results on subjective well-being in Section 3.3. Naturally, the intensity of the emotions may be related to experience and earnings during the experiment. We will report on both, the measures of subjective well-being as well as their relation to interaction success and earnings in the interactive part preceding the questionnaire.

We now come to the third building block of our design. The circle-test used in parts 1 and 3 is a modified version of the ring-test introduced by Liebrand (1984), and was successfully used by Sonnemans, van Dijk and van Winden (2001). It is a task which allows for a quantification of social well-being by determining the readiness of individuals to help or hurt others.

In the circle-test a person's disposition towards another person is measured by a decision which consists in the selection of a point on a circle. Figure 2 shows the circle test used in part 1 of both treatments. Each point on the circle represents an allocation of points to the person who makes the choice $(S)$ and to another person $(O)$. The amounts allocated can be positive or negative, with $S^{2}+O^{2}=1000^{2}$. Each point on the circle also corresponds to a certain angle. ${ }^{12}$ It is possible to choose $S=1000$

\footnotetext{
${ }^{10}$ The reputation formation model of Kreps et al. (1982) can also explain cooperation in both the NCC and the CC conditions.

${ }^{11}$ For discussions of the role of emotions in economic contexts see Loewenstein (2000), Lawler and Thye (1999) and Elster (1998).

${ }^{12}$ The circle appeared on subjects' computer screen. Subjects received computerized instructions
} 


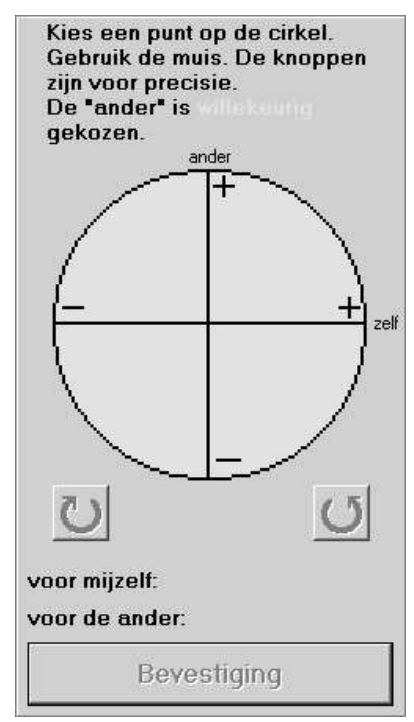

Translation:
Choose a point on the
circle.
Use the mouse. The but-
tons are for precision.
The "other" is arbitrar-
ily chosen.

for myself:
for the other:
Confirmation

Figure 2: The circle test in part 1

and $O=0$. Other choices of $O$ lead to $S<1000$. Importantly, in the experiment these numbers translate into money earnings at the exchange rate of 1000 points equal to US $\$ 2,-$. Hence, decisions in the circle-test have pecuniary consequences.

In both treatments subjects had to make circle-test decisions with respect to other subjects. Before the interactive phase of part 2 began and before even knowing the content of this phase, thus also not knowing whether they were in the NCC or the CC condition, each subject chose an angle with respect to one anonymously and randomly chosen other subject. These initial angles towards a stranger measure the 'social value orientation' or the disposition towards generalized others. The use of social value orientation tests in economic experiments, as for instance in Offerman et al. (1996), has shown that a large fraction of people give positive amounts to others before any interaction has taken place, evidencing positive sentiments towards strangers. Subjects were not informed about the decision of 'their' strangers in the circle test until the very end of the session.

After the end of part 2 subjects were informed that they had to make two new circle-test decisions in part 3 of the experiment. In the $\mathrm{CC}$ each subject chose angles about how to make the decision and had ample opportunity to practice. The angles that subjects could choose were positive (negative) for the cases where the other player obtains some positive (negative amount). 
relative to each of the two other subjects in the triad. In the NCC each subject made one choice relative to his partner and - to keep the number of decisions constant across treatments - another choice relative to a randomly chosen third subject, a stranger. ${ }^{13}$

We collected data for 153 subjects. Each subject participated in only one session. We conducted four CC sessions with 81 subjects in 27 triads. For the NCC 72 subjects participated in 36 dyads in four NCC sessions. We have, therefore, $26[36]^{14}$ and 27 statistically independent observations. All sessions were run computerized at the CREED laboratory at the University of Amsterdam. The average (net of show-up fee) earnings per subject was $€ 23,-$ (approx. $\$ 20,-)$. A typical session lasted approximately 90 minutes. The instructions of the experiment can be downloaded from 'http://www.fee.uva.nl/creed/pdffiles/instr2compwellbe.pdf'.

\section{Results}

We first present the results from the different parts of our design separately. In Section 3.1 we present the results pertaining to the social dilemma games, concentrating on questions of efficiency and earnings. In Sections 3.2 and 3.3 we report on data concerning subjects' disposition towards others and their experienced emotional wellbeing, respectively. In Section 3.4 we examine the relations between earnings in the interactive game and subjects' social and emotional well-being. We formulate our main results as regularities.

\subsection{Competition, efficiency, and earnings}

Figure 3 shows the evolution of average contribution levels over the 30 rounds for both the $\mathrm{CC}$ and the NCC, which also represents attained material efficiency levels. To

\footnotetext{
${ }^{13}$ The reason for measuring emotions and well-being after the interactive part but before the second circle test is that we are interested in the effect of competition and interaction success on people's subjective well-being. Since the questionnaire is not paid we are confident that, by having subjects respond at that particular point, answering the questions did not significantly influence the behavior in the second circle test where monetary incentives were present.

${ }^{14}$ For the NCC we have complete data for only 52 participants (26 pairs). For the other 20 participants we have all information except the decisions in the first circle test. This was due to computer problems in one of the NCC sessions.
} 


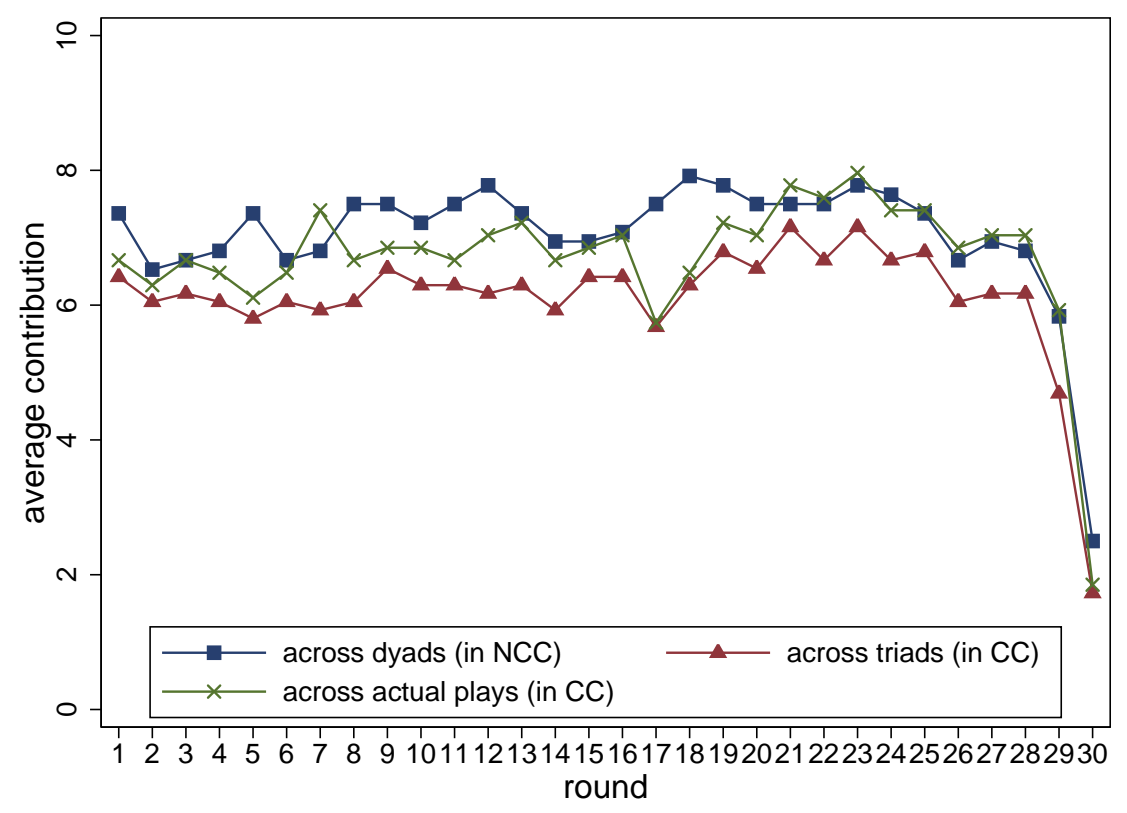

Figure 3: Evolution of average contributions in NCC and CC

interpret the value on the y-axis, recall that the two possible choices are 0 and 10 that can be interpreted as contributions to a public good. For the NCC contributions are the average over the two involved players (dyads), while for the $\mathrm{CC}$ we distinguish between across groups (triads) - the average contribution of all three players A, B and C - and across plays - the average contribution involving A players and the actually chosen $\mathrm{B}$ or $\mathrm{C}$ players. For all three series no large variations across rounds are observed, except for a rather stark end-game effect. ${ }^{15}$ We focus on the comparison of contribution levels across treatments.

\section{Regularity 1}

A. There is no significant difference between contribution levels in the NCC and in the actual plays in the $C C$.

$B$. The contribution levels in the NCC are marginally significantly larger than the contribution levels across triads in the $C C$.

These statements can be statistically supported. For NCC the average contribution level is 7.04 and the standard deviation is 3.39, while for the CC across plays the

\footnotetext{
${ }^{15}$ Such an end-game effect has been found in many other experiments on public goods and social dilemma games. It does not affect our treatment effects.
} 
corresponding values are 6.71 and 3.06. The result from a Mann-Whitney test ${ }^{16}$ does not reject the hypothesis of equal average levels $(p=.2001)$. Across the triads in the $\mathrm{CC}$ the average contribution level is 6.12 and the standard deviation 2.87. Now the Mann-Whitney test detects a marginally significant difference $(p=.0524) .{ }^{17}$

The above result shows that in our experiment competition does not lead to more efficiency. At the same time, the regularities $1 \mathrm{~A}$ and $1 \mathrm{~B}$ together indicate that actual pairings seem to be important. Below we will unveil what is behind this feature of the data.

Another issue is whether in the $\mathrm{CC}$ the long or the short side of the market contributes more. Simple intuition may suggest that player A may sometimes take advantage of his position of power, behave opportunistically and that this may be the main source of inefficiency. Recall, that this kind of opportunistic behavior can be part of an equilibrium strategy. Connected to that is the question whether the short or the long side of the market earns more.

Figure 4 shows histograms, averages, and standard deviations of the earnings per round attained by players in the two conditions. Panel (a) contains the data of average earnings in dyads in the NCC. Panels (b)-(e) show the earnings of players in the CC, where panel (b) indicates the earnings of the A players and panel (c) the earnings of B or $\mathrm{C}$ players whenever they were chosen. Panels (d) and (e) give information about the earnings of B or C players separated by whether they were more or less often chosen. As we will see below this distinction is useful since behavior seems to differ between these two categories. Note, that the last two panels also include data where a player earned only his or her outside payoff of 90 . In the CC we have 27 and in the NCC 36 independent observations.

An inspection of panels (a)-(c) indicates that there is not much difference in earnings in the NCC and the CC and also not between player roles in the CC. The most frequent earnings range is the same in all three panels. Differences in averages appear to be small, while those in the dispersion seem somewhat larger. Our second regularity makes this observation concrete and gives an answer to the question whether the short side of the market can extract rents from the competition on the long side.

\footnotetext{
${ }^{16}$ If not otherwise indicated all tests are two-tailed.

${ }^{17}$ All results remain qualitatively the same when the last two rounds are excluded.
} 


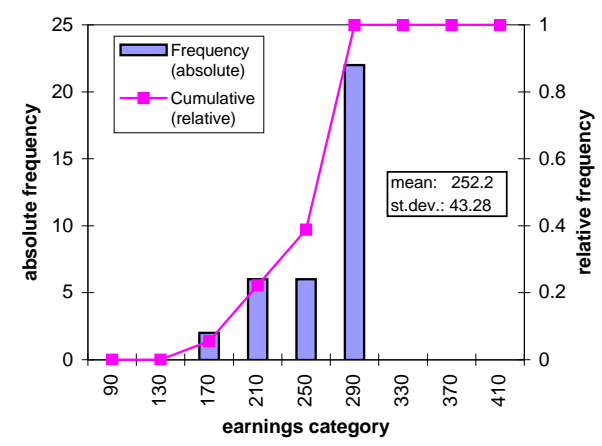

(a) EARNINGS OF PAIRS IN NCC

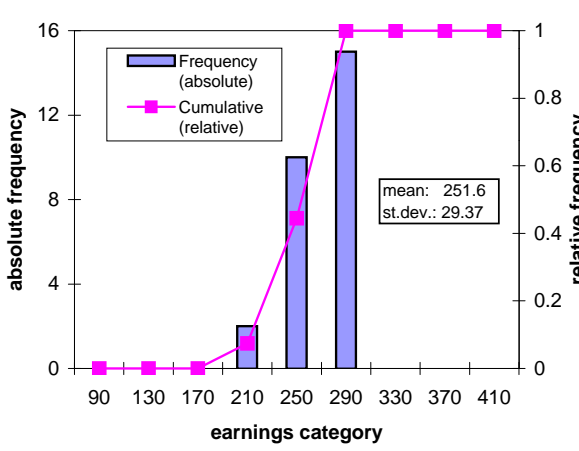

(b) EARnings OF A IN CC

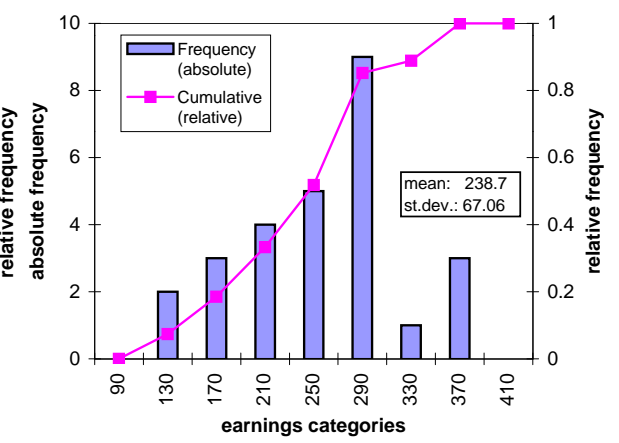

(c) EARNings OF CHOSEN B/C IN $\mathrm{CC}$

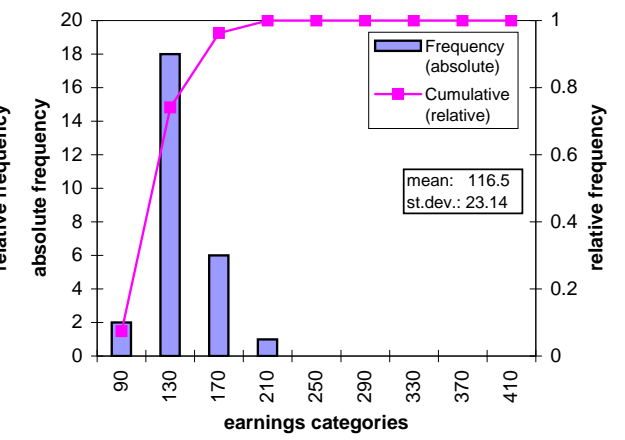

(e) EARnings of LeSS Often CHOSEN B/C IN CC

(d) EARnings of MORE OFTEN CHOSEN B/C IN CC

Note: Earnings in panels (d) and (e) also include earnings of 90 when not chosen. These are absent in panel (c) by definition.

Figure 4: Average (per round) earnings 


\section{Regularity 2}

A. There is no significant difference in average earnings between A players in the $C C$ and players in the $N C C$.

B. There is no significant difference in average earnings between the selected $B$ or $C$ players in the $C C$ and NCC players.

C. The standard deviation of A's earnings across rounds in the $C C$ is significantly larger than for players in the NCC.

For Regularity 2A the Mann-Whitney test gives a $p=.2659$. For Regularity 2B the result for the Mann-Whitney test is $p=.1960$. The standard deviation of earnings across rounds and across A and B players in NCC is $65.43(n=72)$. For A players in CC the standard deviation of earnings across rounds is $89.59(\mathrm{n}=27)$. A Mann-Whitney test shows that this difference is highly significant $(p=.0079)$. Similarly, significant results are obtained when comparing A players' standard deviations in earnings in CC with those of A and B players in the NCC separately.

One can interpret Regularity 2 as a negative result for the allocation of resources. The fact that in many market environments the short side of the market obtains a large part of the available surplus is usually considered to have the allocative virtue of attracting resources to that side. This incentive seems not to be present in our environment, if one compares the short side's earnings with that of the NCC. The fact that the standard deviation of earnings is higher for the A players in the CC than in the NCC also shows that being on the short side of the CC market is not such a favorable position as one might expect at first sight. Competition leads to income uncertainty even for agents on the short side of the market. Intuitively, this might have the consequence that an agent considering entry on the short side of the CC market might not have the right monetary incentive to do so. It would make more sense for him to try to find another player with whom to build up a bilateral relation. This would lead to the same average earnings with less volatility.

We have not yet studied whether player A's actual use of the possibility of changing his partner affects A's earnings. Figure 5 plots the earnings per play of the A players with the more often chosen B/C player (panel (a)) and the earnings of the more often chosen B/C player (panel (b)) against the actual number of plays. The broken horizontal line indicates the median number of plays, which is 22 . The minimum of this 


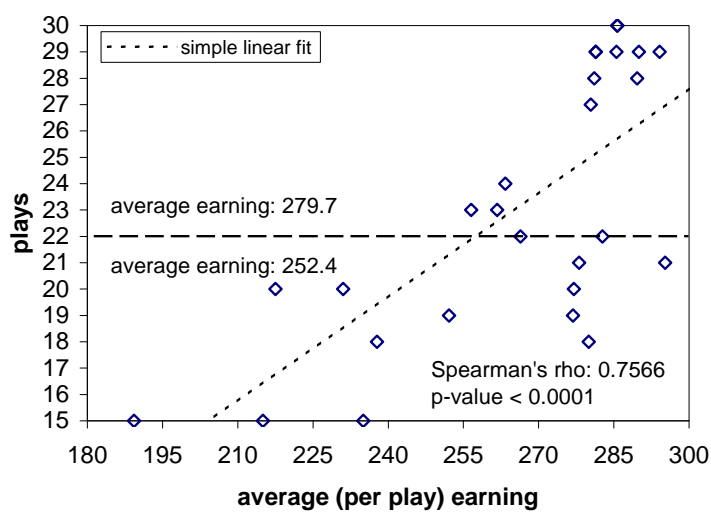

(a) A PLAYER

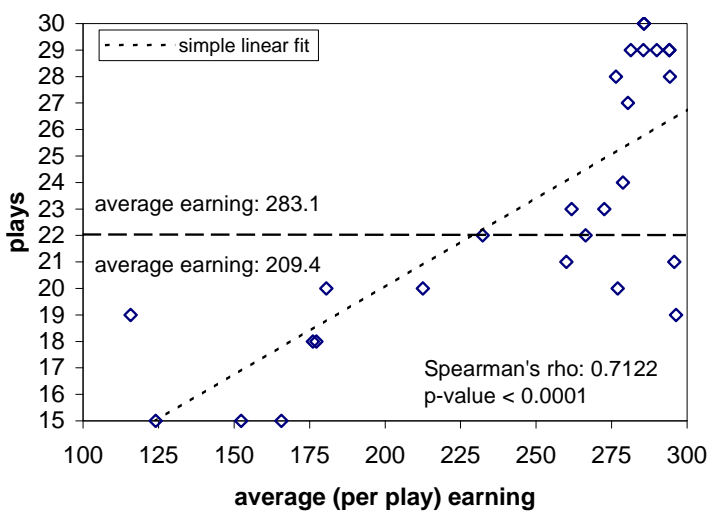

(b) More often Chosen B/C Player

Figure 5: Earnings (per play) of $\mathrm{A}$ and the more often chosen $\mathrm{B} / \mathrm{C}$ player in $\mathrm{CC}$ as a function of the number of plays

variable is 15 rounds and 30 rounds the maximum. As can be seen from the simple linear regression lines there is a clear positive relationship between earnings and the number of plays. This visual impression is corroborated by Spearman rank order statistics (see Figure 5). To further characterize the relationship between earnings per play and the number of plays we calculate the average earnings above and below (or equal) the median number of plays between A players and more often chosen B/C players. These earnings are depicted in Figure 5, above and below the broken horizontal line. They show that players with above median length relationships earn more than those with relationships shorter than 22. Mann-Whitney tests indicate that these differences in earnings are statistically significant. The results are qualitatively the same when we look at earnings per round instead of per play.

\section{Regularity 3}

A. The number of times an A player chooses the same partner correlates significantly positively with A's earnings.

B. Similarly, for those B/C players who are chosen more often, the number of times they are chosen correlates positively with their earnings.

We next turn to A's interaction with the less often chosen partner. Panels (d) and (e) of Figure 4 show the earnings distributions for the more and less often chosen B/C players. As one might expect, the more often chosen players earn significantly more 
than the less often chosen ones. A Wilcoxon signed-ranks test yields that the difference in earnings is statistically significant $(p<.001)$.

For the less often chosen B/C player the same positive relationship between number of plays with A and earnings is found when we look at earnings per round, instead of per play. (Spearman's $\rho=.4941, p=.0121$ ). The median number of plays is 8 . The earnings for less often chosen B/C players with more than eight plays is 128.4 , for those with less or equal to eight plays it is 107.0 (excluding those two who have never been chosen). A Mann-Whitney test shows that this difference in earnings is significant at the $5 \%$ level. Interestingly, the positive relationship between earnings and number of plays breaks down for the less often chosen players when looking at earnings per play. We actually find a significantly negative correlation between the number of rounds chosen and the earnings per play (Spearman's $\rho=-.0 .3999, p=0.0476$ ). This relationship is driven by the fact that some of the less often chosen players free-ride on cooperative A-players in early rounds and A players then do not choose them any more. This drives up the average per play earnings of these free-riders.

Our evidence shows that, for player A, relying on a more bilateral relation is the most promising way to behave. However, even this successful group does not earn significantly more than subjects in the NCC ( $p=.8382$, Mann-Whitney test). Compared to the situation without competition, in the $\mathrm{CC}$ players on the short-side of the market do not profit from choosing one of the players for a long-term relation. For the A's with less than the median number of plays with the same partner there is even some indication that they earn less than subjects in NCC $\left(p=.0696\right.$, Mann-Whitney test). ${ }^{18}$

Why can the A player not profit from the rivalry between B and C, although, as argued in Section 2, large gains by A can be sustained as a (subgame perfect) Nash equilibrium in the CC? The answer could be due to A's partner choice behavior. If A could commit to always changing his trading partner after the partner choosing 0 and never switching after the partner choosing 10, then he would presumably be able to materialize his advantage in the market. However, since this commitment is not possible in our environment, B and C can not be sure of how A will behave. This uncertainty

\footnotetext{
${ }^{18}$ Kollock (1994) and Brown, Falk and Fehr (2003) also find that in stylized incomplete contracting situations people tend to create bilateral relations. However, they do not investigate the impact of competition in such a setting which is our main focus, i.e. they do not study whether bilateral relations in the presence of competition lead to different outcomes than in the absence of competition.
} 
about A's future behavior may lead them to act opportunistically, choosing 0 even after successful cooperation in a round. In consonance with this, A may sometimes switch away from a partner who chose 10. All this could lead to a dilution of A's apparently advantageous situation.

Table 2: Partner switching behavior of A

\begin{tabular}{|c|c|c|c|c|c|c|}
\hline \multirow{4}{*}{$\begin{array}{l}\text { contribution } \\
\text { of partner } \\
\text { of } \mathrm{A} \text { in } t-1\end{array}$} & \multicolumn{6}{|c|}{ contribution of $\mathrm{A}$ in $t-1$} \\
\hline & \multicolumn{3}{|c|}{0} & \multicolumn{3}{|c|}{10} \\
\hline & \multicolumn{3}{|c|}{ contribution of $\mathrm{A}$ in $t$} & \multicolumn{3}{|c|}{ contribution of $\mathrm{A}$ in $t$} \\
\hline & 0 & 10 & Total & 0 & 10 & Total \\
\hline 0 & $\begin{array}{c}67 \\
(\mathrm{n}=135)\end{array}$ & $\begin{array}{c}14 \\
(n=26)\end{array}$ & $\begin{array}{c}81 \\
(\mathrm{n}=161)\end{array}$ & $\begin{array}{c}14 \\
(\mathrm{n}=35)\end{array}$ & $\begin{array}{c}25 \\
(\mathrm{n}=39)\end{array}$ & $\begin{array}{c}39 \\
(n=74)\end{array}$ \\
\hline 10 & $\begin{array}{c}30 \\
(\mathrm{n}=63)\end{array}$ & $\begin{array}{c}10 \\
(n=30)\end{array}$ & $\begin{array}{c}40 \\
(n=93)\end{array}$ & $\begin{array}{c}11 \\
(n=31)\end{array}$ & $\begin{array}{c}28 \\
(\mathrm{n}=424)\end{array}$ & $\begin{array}{c}39 \\
(\mathrm{n}=455)\end{array}$ \\
\hline Total & $\begin{array}{c}97 \\
(\mathrm{n}=198)\end{array}$ & $\begin{array}{c}24 \\
(\mathrm{n}=56)\end{array}$ & $\begin{array}{c}121 \\
(\mathrm{n}=254)\end{array}$ & $\begin{array}{c}25 \\
(\mathrm{n}=66)\end{array}$ & $\begin{array}{c}53 \\
(\mathrm{n}=463)\end{array}$ & $\begin{array}{c}78 \\
(\mathrm{n}=529)\end{array}$ \\
\hline
\end{tabular}

Table 2 reports on partner switching of the A players in the CC. More specifically, it shows the absolute partner switching frequencies of A players in a given round $t$, as a function of A's and the chosen partner's contribution decisions in round $t-1$ and of A's contribution decision in round $t$ itself. To follow up on the possible modes of behavior pointed out in the previous paragraph, focus on the case where both players have contributed 10 in round $t-1$. The frequency of this is 455 , as can be found in the fourth row and last column of the table. The question is whether player A remains contributing 10 and sticks with the same partner after the partner has also contributed 10 in the previous round. The table shows that in 31 occasions player A switches to action 0 and in 11 of these $\mathrm{A}$ also switches partner. In another 28 instances he chooses the cooperative action of 10 but switches partner. In summary, in relation to 455 cases where both players chose 10 in period $t-1 \mathrm{~A}$ 's partner is not rewarded in $t$ in about $13 \%$ instances (59 out of 455 cases). 
Similarly, we may ask whether player A always switches after the partner choosing action 0 in round t- 1 and $\mathrm{A}$ himself choosing 10 in that round, which happens in 74 cases (see, the second row and last column in the table). Out of these, A players reciprocate by choosing 0 in 35 cases (in 14 of these A also switches partner) and chooses 10 but switches in 25 cases. That is, about $19 \%$ (14 out of 74 cases) of the non-cooperative choices of $\mathrm{B} / \mathrm{C}$ players in $t-1$ are not punished in one way or another in $t$. In summary, Table 2 shows that A's reciprocal switching behavior is rather inconsistent with the one that sustains A in obtaining high earnings.

Next to A's switching behavior, tit-for-tat like strategies concerning the contribution decision are also part of the behavior that increases efficiency and earnings. Table 3 shows the relative and absolute frequencies of players' contributions as a function of contributions in the previous round. (The upper part of the table shows the contribution decisions of players labeled $\mathrm{A}$ in round $t$ as a function of the contribution decision of the partner of $\mathrm{A}$, i.e. $\mathrm{B}$ in the $\mathrm{NCC}$ and the chosen $\mathrm{B} / \mathrm{C}$ in the $\mathrm{CC}$, in round $t-1$. The lower part of the table shows the contribution behavior of players labeled B in the NCC and the chosen $\mathrm{B} / \mathrm{C}$ players in the $\mathrm{CC}$ in round $t$ as a function of the contributions of $\mathrm{A}$ players in round $t-1$.) We are mainly interested in possible differences in behavior due two the difference in the competitiveness of the environments. Therefore,our emphasis will be mostly on the comparison between behavior in the two conditions. We focus first on the comparison between behavior in the NCC and that of A players in the CC. Note, that for the NCC A and B players are only different in their labels and the interpretation of the data in the table is immediate. For the A players in the CC, the figure for the contribution decision of $\mathrm{A}$ in round $t$ now includes choices regardless of switching behavior. Observe that both a 0 choice following a 0 and a 10 choice following a 10 are actually less frequent for the A player in the $\mathrm{CC}$ than they are in the NCC data. The frequencies are .723 versus .797 for the 0 choices and .828 versus .926 for the 10 choices. According to $\chi^{2}$-tests the differences of the relative frequencies across conditions are significant at least at the 5 percent level. The fact that switching is possible seems to have the effect that not all of A's 'punishments' of a 0 choice are borne by those who made that choice. Similarly, not all 'rewards' of a 10 choice are reaped by those who made cooperative choices in the previous round. This surely makes it relatively hard to build up a cooperative climate. 
Table 3: Reciprocal behavior in contribution decisions

\begin{tabular}{|c|c|c|c|c|c|c|}
\hline \multirow{4}{*}{$\begin{array}{l}\text { contribution. } \\
\text { of partner } \\
\text { of } \mathrm{A} \text { in } t-1\end{array}$} & \multicolumn{6}{|c|}{ treatment } \\
\hline & \multirow{2}{*}{\multicolumn{3}{|c|}{$\begin{array}{c}\mathrm{NCC} \\
\text { contribution of } \mathrm{A} \text { in } t\end{array}$}} & \multirow{2}{*}{\multicolumn{3}{|c|}{$\begin{array}{c}\mathrm{CC} \\
\text { contribution of } \mathrm{A} \text { in } t\end{array}$}} \\
\hline & & & & & & \\
\hline & 0 & 10 & Total & 0 & 10 & Total \\
\hline \multirow[t]{2}{*}{0} & .797 & .203 & & .723 & .277 & \\
\hline & 243 & 62 & 305 & 170 & 65 & 235 \\
\hline \multirow[t]{2}{*}{10} & .074 & .926 & & .172 & .828 & \\
\hline & 55 & 684 & 739 & 94 & 454 & 548 \\
\hline \multirow{5}{*}{$\begin{array}{l}\text { contribution } \\
\text { of } \mathrm{A} \text { in } t-1\end{array}$} & \multicolumn{6}{|c|}{ treatment } \\
\hline & \multicolumn{3}{|c|}{$\mathrm{NCC}$} & \multicolumn{3}{|c|}{$\mathrm{CC}$} \\
\hline & \multirow{2}{*}{\multicolumn{3}{|c|}{ contribution of $\mathrm{B}$ in $t$}} & \multirow{2}{*}{\multicolumn{3}{|c|}{$\begin{array}{c}\text { contribution of } \\
\text { chosen } \mathrm{B} / \mathrm{C} \text { in } t-1\end{array}$}} \\
\hline & & & & & & \\
\hline & 0 & 10 & Total & 0 & 10 & Total \\
\hline \multirow[t]{2}{*}{0} & .854 & .146 & & .701 & .299 & \\
\hline & 239 & 41 & 280 & 178 & 76 & 254 \\
\hline \multirow[t]{2}{*}{10} & .109 & .891 & & .138 & .862 & \\
\hline & 83 & 681 & 764 & 73 & 456 & 529 \\
\hline
\end{tabular}

Note: Entries depict the relative and absolute frequencies of contribution decisions by $\mathrm{A}(\mathrm{B} / \mathrm{C})$ in period $t$ in dependence of the contribution decisions of the partner of $\mathrm{A}(\mathrm{B} / \mathrm{C})$ in $t-1$.

The data in the southeast portion of Table 3 show that the B/C players in the CC behave - in comparison to players with label B the NCC - similarly to the A players: 0 choices after 0 choices are significantly less frequent in the NCC than in the CC $\left(p<.001, \chi^{2}\right.$-test $)$. Similarly, cooperative choices of 10 after 10 choices are also less frequent in the $\mathrm{CC}$ than in the NCC. This difference is statistically not significant, however $\left(p=.113, \chi^{2}\right.$-test). In summary, the cooperative climate seems to be not worse, perhaps even better, in the NCC than in the CC. All this is in contrast to what equilibrium analysis suggests. In the absence of any commitment possibility it seems very difficult to make the equilibrium intuition work. ${ }^{19}$

\footnotetext{
${ }^{19} \mathrm{~A}$ question that arises is how a stable relation is established. It turns out that first round behavior is important for this. An OLS regression of the total number of plays with the partner chosen in
} 
In this section we have looked at the impact of competition in the interaction phase in isolation. In Section 3.2 below, we will relate this to the results of our measurements of social and emotional well-being.

\subsection{Competition and the disposition toward others}

Table 4 presents the averages and standard deviations of the angles observed in the circle tests, distinguishing the NCC from the CC. For the CC we also distinguish between player types and, for the B/C players, between more and less often chosen ones.

Focus first on initial angles. Recall, that these were recorded before subjects were informed about the content of any of the remaining parts of the experiment. Hence, these angles can not be affected by behavior or even by expectations about behavior in the incomplete contract game. The average initial angles are 15.37 degrees in the NCC and 14.01 in the CC. ${ }^{20}$ The difference is statistically not significant ( $p=.8032$, MannWhitney test). In the CC, we also do not find a statistically significant difference in initial angles between those subjects who became an A player and those who became a $\mathrm{B}$ or $\mathrm{C}$ player. A look at the initial angles of the subsequently more and less often chosen B/C players (19.20 vs. 7.96 degrees) hints towards a sorting out of the initially more selfish B/C players. However, this difference is statistically not significant $(p=0.218$, Mann-Whitney test).

Our main interest is in whether and how competition and experience during the interaction phase affect people's disposition towards others. We, therefore, focus on changes in the angles and not on their levels. For both conditions we observe a general tendency for angles to decrease from the pre-game to the post-game situation. This general 'decay' is in line with the results of van Dijk, Sonnemans and van Winden (2002). More importantly, the observed changes differ across conditions and roles and some of the changes are significant while others are not. The pattern of these differences and significances is summarized in the following regularity.

the first round as dependent variable and the first round decision of this partner and of A herself as independent variables finds strongly significant positive effects of these variables.

${ }^{20} \mathrm{An}$ angle of 15 degrees implies a transfer to the other person of approximately 260 points. 
Table 4: Disposition towards others - average angles in the circle tests

\begin{tabular}{|c|c|c|c|c|c|c|c|c|c|c|c|c|c|}
\hline & \multicolumn{5}{|c|}{ initial angle of } & \multicolumn{8}{|c|}{ final angle of } \\
\hline & all & $\mathrm{A}$ & $\mathrm{B} / \mathrm{C}$ & more chosen & less chosen & $\begin{array}{l}\text { towards } \\
\text { partner }\end{array}$ & $\begin{array}{l}\text { towards } \\
\text { third party }\end{array}$ & $\begin{array}{c}\text { A } \\
\text { towards } \\
\text { more chosen }\end{array}$ & $\begin{array}{c}\text { A } \\
\text { towards } \\
\text { less chosen }\end{array}$ & $\begin{array}{c}\text { more chosen } \\
\text { towards } \\
\text { A }\end{array}$ & $\begin{array}{c}\text { more chosen } \\
\text { towards } \\
\text { less chosen }\end{array}$ & $\begin{array}{c}\text { less chosen } \\
\text { towards } \\
\text { A }\end{array}$ & $\begin{array}{l}\text { less chosen } \\
\text { towards } \\
\text { more chosen }\end{array}$ \\
\hline $\mathrm{NCC}$ & 15.37 & & & & & 10.67 & 9.68 & & & & & & \\
\hline & $(18.40)$ & & & & & $(24.17)$ & $(15.49)$ & & & & & & \\
\hline & {$[\mathrm{n}=52]^{a}$} & & & & & {$[\mathrm{n}=52]^{c}$} & {$[\mathrm{n}=52]^{c}$} & & & & & & \\
\hline \multirow[t]{3}{*}{$\mathrm{CC}$} & 14.01 & 14.90 & 13.58 & 19.20 & 7.96 & & & 14.54 & 6.93 & 12.49 & 12.59 & -4.19 & 5.95 \\
\hline & $(26.03)$ & $(19.43)$ & $(28.83)$ & $(21.99)$ & $(33.81)$ & & & $(20.14)$ & $(14.40)$ & $(19.24)$ & $(16.79)$ & $(27.03)$ & $(13.61)$ \\
\hline & {$[\mathrm{n}=80]^{b}$} & {$[\mathrm{n}=26]^{b}$} & {$[\mathrm{n}=54]$} & {$[\mathrm{n}=27]$} & {$[\mathrm{n}=27]$} & & & {$[\mathrm{n}=26]$} & {$[\mathrm{n}=26]$} & {$[\mathrm{n}=27]$} & {$[\mathrm{n}=27]$} & {$[\mathrm{n}=27]$} & {$[\mathrm{n}=27]$} \\
\hline
\end{tabular}

Note: ${ }^{a}$ observations of one session are missing due to technical problems; ${ }^{b}$ one missing observation; ${ }^{c}$ without observations that correspond to the missing observations in the first circle test $\left(\right.$ see $\left.^{a}\right){ }^{d}$ without observation that corresponds to the missing observation in the first circle test $\left(\right.$ see $\left.^{b}\right)$; in the three cases where both B/C players are chosen exactly 15 times the average angles of the two players is used when calculating the angles for the "more often" and "less often" chosen players. Standard deviations in parentheses. 


\section{Regularity 4}

A. In the NCC, players' disposition towards their partners are not statistically signifcant, whereas there is a significant decrease towards third parties.

$B$. In the CC, A players' disposition towards the more often chosen player does not change, but decreases significantly towards the less often chosen partners.

$C$. In the $C C$, the more often chosen B/C players' disposition towards $A$ does not change, and decreases marginally significantly towards their less often chosen counterparts.

$D$. In the $C C$, the less often chosen B/C players' disposition towards $A$ decreases significantly, but does not change towards their more often chosen counterparts.

For the NCC we find that players' disposition towards their partners has - in statistical terms - stayed constant, while the disposition towards third parties has diminished. For the comparison of the initial angles (15.37) with the final angles towards the partners $(10.67)$ the Wilcoxon signed-ranks test yields $p=.1775$. In contrast, the initial angle is significantly different from the final angle towards the third party, which is 9.68 $(p=.0132$, Wilcoxon signed-ranks test) .

How does this compare to the pattern in the CC? Here we need to look both at $\mathrm{A}$ and $\mathrm{B} / \mathrm{C}$ players. In addition we make, as above, the distinction between more and less often chosen $\mathrm{B} / \mathrm{C}$ players. Part $\mathrm{B}$ of the above regularity captures the $\mathrm{A}$ players' changes. The fact that - compared to their initial disposition - they do not significantly modify their disposition towards the more often chosen partner can be directly observed in Table 4 where A's average initial angle is 14.90 and the average final angle towards the more often chosen partner is 14.54 with very similar standard deviations. Concerning the less often chosen partner the final angle decreases to 6.93 and a Wilcoxon signed-ranks test indicates that this change is significant $(p=.0203)$.

For the more often chosen B/C player the decrease in the angle from 19.20 (initial angle) to 12.49 (final angle towards the A player) is statistically not significant ( $p=$ .1650, Wilcoxon signed-ranks test). The decrease to 12.59 (final angle towards the less often chosen B/C fellow player) is statistically marginally significant according to a Wilcoxon signed-ranks test $(p=.0552)$.

For the less often chosen $\mathrm{B} / \mathrm{C}$ players the decrease in the angle from the initial value of 7.96 to -4.19 (final angle towards the A player) is statistically highly significant 
( $p=.0018$, Wilcoxon signed-ranks test). Note, that the negative angle implies that less often chosen $\mathrm{B} / \mathrm{C}$ players are ready to give up money in order to reduce the earnings of A players. The decrease to 5.95 (final angle towards more often chosen B/C fellow players) is statistically insignificant ( $p=.4178$, Wilcoxon signed-ranks test).

In summary, subjects in the NCC, where trading partners had to stay together for all 30 rounds, and subjects in the CC who interact often with each other show no significant decrease in their disposition towards each other. Simultaneously, in the NCC a significant decrease in the disposition towards third parties is observed, as it is also the case in the CC between those subjects who interacted relatively little with each other. A plausible interpretation of these observations is that subjects suffer from a considerable baseline distress (leading to some general decay in angles), and that, at the same time, they exhibit some specific goodwill concerning only those they traded with relatively often. The latter is possibly related to success in the interaction. This might indicate that between those who had many (successful) trades there exists a good basis for possible future interactions. At the same time the observations also indicate that with less often chosen partners no good basis for future trade might exist. We examine the relation of interaction success and the disposition towards others in the next section.

Figure 6 summarizes the changes in disposition towards others for the two conditions. (In the figure a '- ' indicates a statistically significant decrease and a ' 0 ' indicates

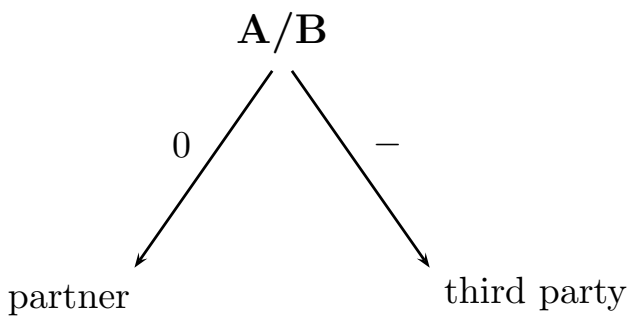

(a) Changes in The NCC
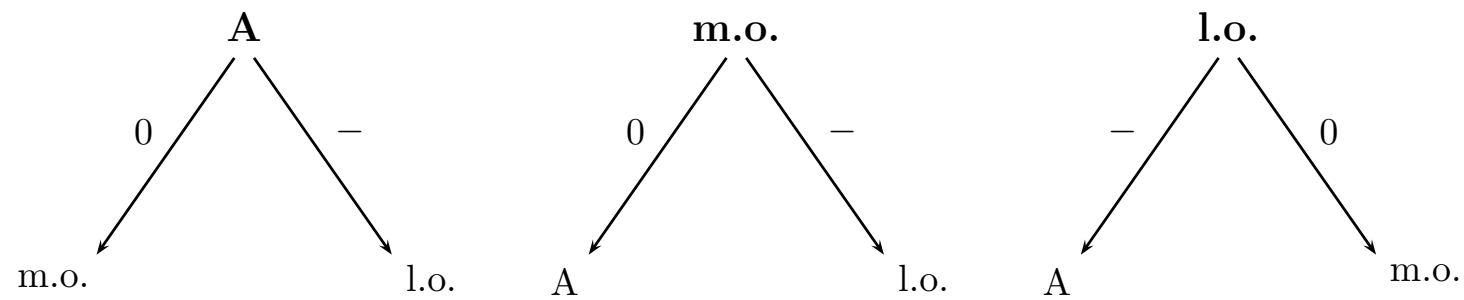

(b) Changes in the CC

Figure 6: Graphical representation of the changes in disposition towards others 
no statistically significant change; 'm.o.' and 'l.o.' stands for 'more often chosen B/C player' and 'less often chosen B/C player', respectively.) Note, that the pattern of changes in the CC (panel (b)) can not be easily reconciled with notions of inequality aversion. Both the A players and the more often chosen - and, hence, succesful - B/C players exhibit a significant decrease in the angle towards the remaining unsuccesful B/C player, who also earned less (recall Figure 4, panels (b), (d), and (e)). If players were trying to settle accounts in terms of payoffs one should expect the opposite. The behavior of the less often chosen B/C can also not be explained solely in terms of payoffs. Although the average final angle towards A is negative (-4.19), which means that A's payoff is being decreased, the average final angle towards the more succesful B/C players remains positive and does also not decrease significantly.

\subsection{Subjective well-being and emotions}

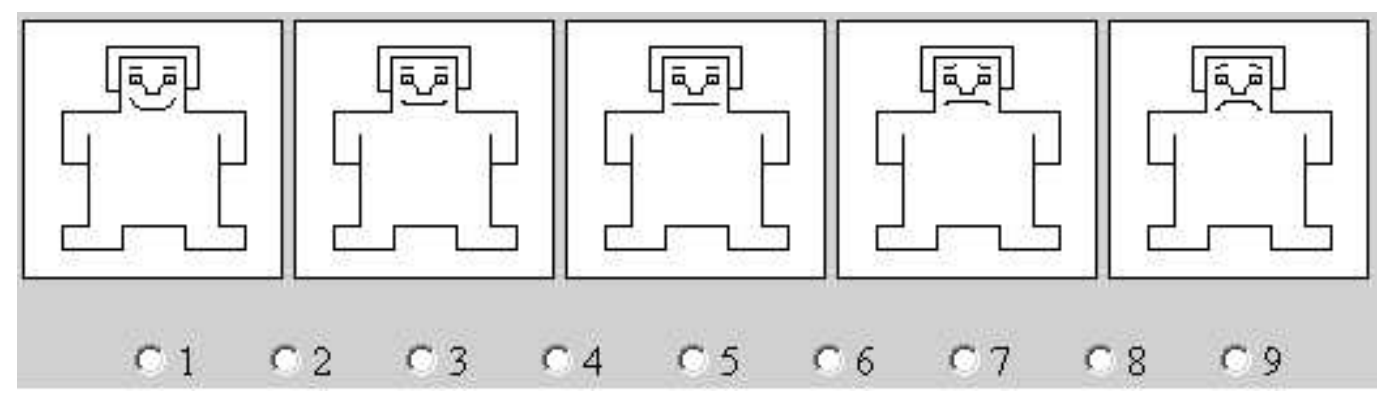

Figure 7: Global measure of subjective well-being

We are using both a global measure as well as a list of experienced emotions to elicit subjects' subjective well-being. Our global measure of subjective well-being is shown in Figure 7. After the interaction phase, subjects were asked to mark the number that best corresponded to their general mood in relation to the facial expressions of the socalled Self-Assessment Manikin. ${ }^{21}$ Clearly, a 1 corresponds to the highest level and a 9 to the lowest level of subjective well-being. In the reported measure that we use below we have inverted the score obtained from subjects' decisions in Figure 7, so that 1 is the minimum and 9 the maximum, to make it more easily comparable to the emotions scores reported below. Table 5 shows in the one before last row (labeled 'well-being') the average values of the measure for the different conditions and types of players. Our

\footnotetext{
${ }^{21}$ These figures, developed by Lang (1980) are reprinted from Sonnemans (1991).
} 
Table 5: Averages of individual emotion scores and global measure of subjective well-being across conditions and roles

\begin{tabular}{|c|c|c|c|c|}
\hline \multirow[b]{2}{*}{ emotion } & \multicolumn{4}{|c|}{ condition-role } \\
\hline & CC-A & CC-B/C m.o. & CC-B/C 1.o. & $\mathrm{NCC}$ \\
\hline $\operatorname{sad}^{a, b, c, e, f}$ & 1.93 & 2.70 & 4.07 & 2.06 \\
\hline happy $^{a, b, c, d, f}$ & 5.04 & 4.26 & 3.00 & 4.07 \\
\hline shame $^{a}$ & 2.11 & 1.54 & 2.28 & 1.82 \\
\hline $\operatorname{pride}^{b, c, f}$ & 3.78 & 4.00 & 2.78 & 3.75 \\
\hline fear $^{a, e}$ & 1.48 & 2.04 & 2.04 & 1.61 \\
\hline $\operatorname{envy}^{a, b, e, f}$ & 1.85 & 3.15 & 3.67 & 2.43 \\
\hline relief $f^{b, c, f}$ & 3.59 & 3.70 & 2.48 & 3.47 \\
\hline anger $^{b, c, f}$ & 2.07 & 2.80 & 4.46 & 2.75 \\
\hline joy $^{b, c, d, f}$ & 4.74 & 4.19 & 2.56 & 3.75 \\
\hline guilt & 2.00 & 2.02 & 2.32 & 1.68 \\
\hline irritation $^{a, b, d, f}$ & 2.26 & 3.37 & 4.44 & 3.26 \\
\hline surprise $^{f}$ & 3.37 & 3.48 & 4.33 & 3.28 \\
\hline contempt $^{b, f}$ & 2.04 & 3.17 & 3.76 & 2.44 \\
\hline well-being $^{a, b, c, d, f}$ & 7.85 & 6.09 & 3.50 & 6.40 \\
\hline no. of obs & 27 & 27 & 27 & $72^{\dagger}$ \\
\hline \multicolumn{5}{|c|}{$\begin{array}{l}\text { Note: Scores for the individual emotions range from } 1 \text { ("not at all") to } 7 \\
\text { ("very intense") and scores for well-being range from } 1 \text { ("very bad") to } 9 \\
\text { ("very good"). }{ }^{a} \text { significant difference between CC-A and CC-B/C m.o., }{ }^{b} \\
\text { significant difference between CC-A and CC-B/C l.o., }{ }^{c} \text { significant difference } \\
\text { between CC-B/C m.o. and CC-B/C l.o., }{ }^{d} \text { significant difference between } \\
\text { CC-A and NCC, }{ }^{e} \text { significant difference between CC-B/C m.o. and NCC, } \\
f \text { significant difference between CC-BC l.o. and NCC; all significances at } \\
\text { least at } 5 \text { percent level, Mann-Whitney rank sum tests, two-tailed; }{ }^{\dagger} \text { for } \\
\text { pride } n=71 \text { due to one missing observation. }\end{array}$} \\
\hline
\end{tabular}

main interest lies in differences across the NCC and the $\mathrm{CC}$ and across the different player situations within the CC. Regularity 5 summarizes these differences. Recall that these comparisons are between subjects.

\section{Regularity 5}

A. Subjective well-being is significantly lower for the NCC players than for the A players in the $C C$.

B. Subjective well-being is significantly higher for the NCC players than for the less often chosen $B / C$ players in the $C C$.

C. Subjective well-being is not significantly different between the NCC players and the more often chosen $B / C$ players in the $C C$. 
D. Subjective well-being is significanly higher for the A players in the CC than for the $B / C$ players.

E. In the CC, subjective well-being is significantly lower for the less often chosen than for the more often chosen $B / C$ players.

The superscripts in Table 5 indicate significant differences of pairwise comparisons across player situations and conditions. For our global measure of subjective well-being all pairwise comparisons appear to be significant at least at the 5 percent level, with only one exception. (There is no significant difference between players in the NCC and the more often chosen $\mathrm{B} / \mathrm{C}$ players in the CC.) Note, that in the $\mathrm{CC}$ the levels of our global measure of subjective well-being are different between all three player situations. Being on the short or long side of the market does make a difference for subjective well-being. Those on the long side feel significantly worse than players on the short side. Moreover, being mostly excluded on the long side of the market has an additional negative impact on subjective well-being. Observe also that, in comparison to the NCC, the reported scores of our galobal measure in the CC are at a higher, a lower and a similar level, depending on the situation players are in. Hence, competition has led to an inequality in subjective well-being without generating material efficiency gains. Note also that average scores of our global measure of subjective well-being across all players in the $\mathrm{CC}$ is with 5.81 lower than for subjects in the NCC, where it is 6.40 , although not significantly so $(p=0.1884)$.

Next to the the global measure of subjective well-being we also asked subjects to report on a number of individual emotions. Besides more specific information on the emotional state of the players this provides us also with a check of our global measure. We expect that negative (positive) emotions are negatively (positively) correlated with our global measure. Table 6 shows these correlations between our general measure and the individual emotions. In the table a ${ }^{*}$ denotes a statistically significant correlation coefficient. On the positive side happiness, pride, joy, and relief indeed show a significantly positive correlation with our global measure of subjective well-being. As the negative emotions sadness, envy, anger, irritation, and contempt turn out to be stronly negatively correlated with our measure. In summary, subjects reporting good subjective well-being, in the global measure, also report higher scores on positive and lower scores on negative emotions. This sustains the interpreation that our global mea- 
Table 6: Correlation of emotions with global

\begin{tabular}{lccc}
\multicolumn{4}{c}{ measure of subjective well-being } \\
\hline \hline \multirow{3}{*}{ emotion } & $\begin{array}{c}\text { correlation } \\
\text { coefficient }\end{array}$ & emotion & $\begin{array}{c}\text { correlation } \\
\text { coefficient }\end{array}$ \\
\hline sadness & $-.5997^{*}$ & anger & $-.6915^{*}$ \\
& $(.0000)$ & & $(.0000)$ \\
happiness & $.7319^{*}$ & joy & $.7579^{*}$ \\
& $(.0000)$ & & $(.0000)$ \\
shame & -.0568 & guilt & -.0234 \\
& $(.4852)$ & & $(.7740)$ \\
pride & $.4013^{*}$ & irritation & $-.6489^{*}$ \\
& $(.0000)$ & & $(.0000)$ \\
fear & -.0902 & surprise & $-.2635^{*}$ \\
& $(.2673)$ & & $(.0010)$ \\
envy & $-.4401^{*}$ & contempt & $-.4374^{*}$ \\
& $(.0000)$ & & $(.0000)$ \\
relief & $.3563^{*}$ & & \\
& $(.0000)$ & & \\
\hline Note: p-values in parentheses; ${ }^{\dagger} \ldots$ & for pride $n=152$ \\
due to one missing observation. &
\end{tabular}

sure indeed measures how people feel and also demonstrates the close relation between subjective well-being in a more general sense and the intensity of individual emotions.

Table 5 shows the average reported intensity of each of the individual emotions for each of the four possible positions in the interaction phase in the two conditions. For the emotions the score 1 represents the lowest experienced intensity and the score 7 the highest. In view of the results concerning the general well-being and its relation with the emotions the observed patterns seem quite natural. Pairwise comparisons of the emotion scores between players' positions lead us to the following regularity.

\section{Regularity 6}

A. The A players in the CC appear to be in a better emotional state that the NCC players.

$B$. The less often chosen $B / C$ players in the $C C$ are in a worse emotional state than the NCC players.

$C$. In the $C C$ the $A$ players exhibit a better emotional state than the $B / C$ players. 
$D$. In the $C C$ the less often chosen $B / C$ players are in a much worse emotional state than the A players and the more often chosen B/C players.

The supercripts at the emotion names in Table 5 indicate significant differences in the pairwise comparisons across conditions and player roles. In relation to Regularity $6 \mathrm{~A}$ subjects in the NCC report significantly lower levels of positive emotions like happiness and joy and a significantly higher level of the negative emotion irritation than the A players in the CC. Concerning Regularity $6 \mathrm{~B}$, the less often chosen $\mathrm{B} / \mathrm{C}$ players report significantly higher intensities of the negative emotions sadness, envy, anger, irritation, and contempt and significantly lower intensities of the positive emotions happiness, pride, relief, and joy than players in the NCC. Concerning Regularity 6C, the A players report a significantly higher intensity of happiness and significantly lower intensities of sadness, envy, and irritation than both the more and less often chosen B/C players. Regarding, Regularity 6D, the less often chosen B/C players report significantly higher intensities of the negative emotions sadness, envy, and anger and significantly lower intensities of the positive emotions happiness, pride, relief, and joy than the more often chosen B/C players.

In summary, the evidence presented in Sections 3.2 and 3.3 documents that there exists a clear relation between people's social and subjective well-being, on one hand, and their position in the market, on the other hand. In particular, being on the long side of the market makes people less willing to help others and reduces their subjective well-being, which is reinforced for those often excluded from trading.

\subsection{Earnings and well-being}

Both social and subjective well-being are affected by people's position in the interaction phase. What remains to be discussed is to what extent these changes can be explained by interaction success and differences in earnings.

Table 7 presents regression results pertaining to the A players' choices of final angles towards their partners as a function of initial angle choices and other independent variables pertaining to various features of the interaction phase. For player A we distinguish between changes of disposition towards the more and the less frequently chosen partners. Equations (a) and (b) represent in each case the results for the two 
Table 7: The determinants of the final angles of A players in CC

(Seemingly unrelated regressions)

\begin{tabular}{|c|c|c|c|c|c|c|c|c|}
\hline & \multicolumn{8}{|c|}{$\begin{array}{l}\text { A player towards more often (\#a equations) and } \\
\text { less often (\#b equations) chosen B/C player }\end{array}$} \\
\hline & (1a) & (1b) & $(2 a)$ & $(2 b)$ & $(3 a)$ & $(3 b)$ & $(4 a)$ & $(4 b)$ \\
\hline Initial & $.4560^{* *}$ & .1601 & $.4240^{*}$ & .1817 & $.4592^{* *}$ & .1560 & $.4631^{*}$ & .1787 \\
\hline angle & $(.010)$ & $(.258)$ & $(.026)$ & $(.206)$ & $(.010)$ & $(.292)$ & $(.017)$ & $(.226)$ \\
\hline Earnings & $.3164^{*}$ & -.0037 & & & & & .1124 & .0029 \\
\hline per play & $(.039)$ & $(.927)$ & & & & & $(.337)$ & $(.936)$ \\
\hline$\#$ of & $-2.218^{*}$ & .8431 & & & $-6.804^{*}$ & .9735 & & \\
\hline plays & $(.020)$ & $(.201)$ & & & $(.030)$ & $(.550)$ & & \\
\hline Total & & & -.0014 & .0025 & .0168 & -.0007 & & \\
\hline Earnings & & & $(.501)$ & $(.313)$ & $(.055)$ & $(.917)$ & & \\
\hline \multirow[t]{2}{*}{ Constant } & -25.42 & -.3970 & 17.58 & 1.318 & $60.06^{*}$ & -.9205 & -21.57 & 4.421 \\
\hline & $(.427)$ & $(.956)$ & $(.213)$ & $(.792)$ & $(.009)$ & $(.865)$ & $(.497)$ & $(.531)$ \\
\hline$R^{2}$ & 0.3157 & 0.1313 & .2012 & .1051 & .3156 & .1317 & .1719 & .0589 \\
\hline$N^{a}$ & 24 & 24 & 24 & 24 & 24 & 24 & 24 & 24 \\
\hline
\end{tabular}

equations of a specification of seemingly unrelated regressions. The (a) equation is always the one for the more often chosen partner and the (b) equation is the one for the less often chosen partner. We will compare the results for the A player with those for the B/C players. Table 8 shows the results for the more often chosen and Table 9 for the less often chosen ones. In both these tables the (a) equations pertain to the A player and the (b) equations to the other B/C player.

In all the specifications shown in Tables 7-9 we have excluded the extreme case when a B/C player was never chosen, which happend in two triads. All our regressions are based on statistically independent data points. Three of the independent variables, earnings per play, number of plays, and total earnings, relate to the interaction phase. The other two explanatory variables do not correspond to any specifics of the interaction success. The initial angle reflects the general disposition to help others and the constant can be viewed to represent satisfaction or lack thereof with the process as a whole. 
Table 8: The determinants of the final angles of more often chosen $\mathrm{B} / \mathrm{C}$ players in $\mathrm{CC}$ (Seemingly unrelated regressions)

\begin{tabular}{|c|c|c|c|c|c|c|c|c|}
\hline & \multicolumn{8}{|c|}{$\begin{array}{c}\text { More often chosen B/C player towards A (\#a equations) and } \\
\text { less often (\#b equations) chosen B/C player }\end{array}$} \\
\hline & $(5 a)$ & $(5 b)$ & $(6 a)$ & $(6 b)$ & $(7 a)$ & $(7 b)$ & $(8 a)$ & $(8 b)$ \\
\hline Initial & .2559 & $.5245^{* *}$ & .2440 & $.5245^{* *}$ & .2360 & $.5245^{* *}$ & .2800 & $.5245^{* *}$ \\
\hline angle & $(.101)$ & $(.000)$ & $(.113)$ & $(.000)$ & $(.134)$ & $(.000)$ & $(.067)$ & $(.000)$ \\
\hline Earnings & .1042 & & & & & & $.1464^{* *}$ & \\
\hline per play & $(.227)$ & & & & & & $(.007)$ & \\
\hline$\#$ of & .6600 & & & & .5018 & & & \\
\hline plays & $(.541)$ & & & & $(.826)$ & & & \\
\hline Total & & & $.0036^{*}$ & & .0026 & & & \\
\hline Earnings & & & $(.013)$ & & $(.589)$ & & & \\
\hline \multirow[t]{2}{*}{ Constant } & $-31.86^{*}$ & 2.718 & -12.11 & 2.718 & -17.49 & 2.718 & $-27.70^{*}$ & 2.718 \\
\hline & $(.041)$ & $(.422)$ & $(.186)$ & $(.422)$ & $(.505)$ & $(.422)$ & $(.045)$ & $(.422)$ \\
\hline$R^{2}$ & .2751 & .4640 & .2587 & .4640 & .2618 & .4640 & .2572 & .4640 \\
\hline$N$ & 25 & 25 & 25 & 25 & 25 & 25 & 25 & 25 \\
\hline
\end{tabular}

Focus first on the initial angle variable and compare the results across Tables 7-9. For the A player the coefficient vis-à-vis the more often chosen partner is positive and significant, whereas vis-à-vis the less often chosen it is not significant (although also positive) in all specifications. For the more often chosen B/C players things are quite different. Here the coefficient vis-à-vis the less often chosen counterpart, i.e. the rival of the player under consideration, is significantly positive in all specifications. In contrast, the coefficient pertaining to the A player is not significant in any specification. For the less often chosen $\mathrm{B} / \mathrm{C}$ player coefficients pertaining to the A player are significantly positive, whereas those related to the more often chosen B/C player are not significant. Thus, the influence of subjects' initial disposition towards others on the disposition towards their trading partners after the interaction differs across the different positions in the market, ceteris paribus.

To complete the picture of the effect of non-interaction variables we now focus on the values of the constant term. For the A player the constant terms are not significantly 
Table 9: The determinants of the final angles of less often chosen B/C players in CC (Seemingly unrelated regressions)

\begin{tabular}{|c|c|c|c|c|c|c|c|c|}
\hline & \multicolumn{8}{|c|}{$\begin{array}{c}\text { Less often chosen B/C player towards A (\#a equations) and } \\
\text { more often (\#b equations) chosen B/C player }\end{array}$} \\
\hline & $(9 a)$ & $(9 \mathrm{~b})$ & $(10 \mathrm{a})$ & $(10 b)$ & (11a) & (11b) & $(12 \mathrm{a})$ & $(12 b)$ \\
\hline Initial & $.6827^{* *}$ & .1051 & $.6750^{* *}$ & .1051 & $.6724^{* *}$ & .1051 & $.6860^{* *}$ & .1051 \\
\hline angle & $(.000)$ & $(.146)$ & $(.000)$ & $(.146)$ & $(.000)$ & $(.146)$ & $(.000)$ & $(.146)$ \\
\hline Earnings & .009 & & & & & & -.0015 & \\
\hline per play & $(.776)$ & & & & & & $(.960)$ & \\
\hline \# of & .5319 & & & & -.2978 & & & \\
\hline plays & $(.417)$ & & & & $(.763)$ & & & \\
\hline Total & & & .0035 & & .0044 & & & \\
\hline Earnings & & & $(.220)$ & & $(.366)$ & & & \\
\hline \multirow[t]{2}{*}{ Constant } & -15.89 & 4.097 & $-15.14^{* *}$ & 4.097 & $-14.22^{* *}$ & 4.097 & -9.407 & 4.097 \\
\hline & $(.149)$ & $(.063)$ & $(.005)$ & $(.063)$ & $(.010)$ & $(.063)$ & $(.215)$ & $(.063)$ \\
\hline$R^{2}$ & .6406 & .0781 & .6479 & .0781 & .6554 & .0781 & .6487 & .0781 \\
\hline$N$ & 25 & 25 & 25 & 25 & 25 & 25 & 25 & 25 \\
\hline
\end{tabular}

different from zero except in equation (3a), where it is significantly - and strongly positive. This is quite in contrast with the results for the more often chosen B/C player where the constants in the (a) equations are always negative and in (5a) and (8a) significantly so. In the (b) equations the constant is never significantly different from zero. Hence, while - other things equal - A's final disposition towards the trading partners did not change or even increased, the regressions indicate that the more often chosen B/C players have decreased - even substantially - their disposition towards the A players. A similar pattern can be observed for the less often chosen B/C players: the constants in the (a) equations are always negative, and significantly so in equations (10a) and (11a). Hence, the process of interaction as a whole seems to further or at least does not decrease A players' disposition to help their interaction partners. For the players on the long side of the market, however, it holds that the process of interaction decreases their disposition towards those on the short side of the market. 
We now turn to the coefficients for the variables reflecting interaction success. We start here with the results for the less often chosen B/C players shown in Table 9. It is clear from the table that neither earnings nor the number of plays play a significant role in the determination of the final angles towards the A player. A plausible reason for this outcome is that for the less often chosen players actually not much interaction took place and that most of the variation of the dependent variable is captured by the non-interaction variables. For the more often chosen $\mathrm{B} / \mathrm{C}$ players the picture is quite different (Table 8). Here earnings have a significantly positive influence on the final disposition towards the A player. This holds for the specification with total earnings (equation (6a)) as well as for the specification with earnings per play in equation (equation (8a)).

A's interaction success never significantly affects A's disposition towards the less often chosen player on the long side of the market. With respect to the more often chosen partner this is quite different (Table 7). In equation (1a) earnings per play have a significantly positive effect and in equation (3a) we see a marginally significantly positive coefficient for total earnings. Hence, the more A players earned in partnerships with the more often chosen partners the more positive is their disposition towards them. Interestingly, in both equations, (1a) and (3a), the number of plays have a significantly negative effect on the A players final angles. At first sight this may seem surprising and counterintuitive. We offer the following interpretation. For constant earnings, the negative coefficient may reflect a satiation effect in the following sense. A longer partnership per se does not lead to more satisfaction when the earnings do not increase with the length of the partnership. The higher earnings are becoming a normal event. Staying together for one more round without earning more may than lead to a certain frustration. Of course, simple boredom from playing with the same person all the time might also have such an effect. ${ }^{22}$

For the NCC we find no relation between interaction succces and final disposition towards both the interaction partner and the third party. We ran several variations of

\footnotetext{
${ }^{22}$ For equations (1a) and (1b) a chi square test rejects the equality of the coefficients corresponding to the initial angles only at the 10 percent level $(p=.0611)$. The differences in the earnings per play and number of rounds coefficients are both significant at the 5 percent level $(\mathrm{p}=.0405$ and $\mathrm{p}=.0210$, respectively). Less often chosen partners seem not to be held accountable for low earnings and the frustration with the length of a relationship only appears when the interaction is sufficiently frequent.
} 
seemingly unrelated regressions with disposition towards the interaction partner and the third party as dependent variables. In all regressions only the initial angle turns out to be significant.

Overall, the factors related to people's changes in disposition towards others differ across the different competitive experiences and roles in the market. Our main findings in this respect are summarized in the following result.

\section{Regularity 7}

A. Interaction success does not significantly affect NCC players' disposition towards others.

$B$. In the $C C$, interaction success significantly affects A players' and more often chosen $B / C$ players' disposition towards each other positively. For the less often chosen players it has no significant effect.

$C$. In the $C C$, when controlling for interaction success $B / C$ players exhibit a decrease in their disposition towards A players, while A players do not show any (negative) change in their disposition towards $B / C$ players.

Interaction success does not seem to be the only and possibly not even the most important force that alters subjects' disposition towards others and, hence, social well-being. People's competitive position itself seems crucial for understanding how their psychology and social orientation is affected by market participation.

In this respect it is interesting to note that, though we find no direct effect of interaction success on the disposition towards others in NCC, there are strong indications that there is an indirect effect. In NCC, we find a direct positive effect of interaction success on subjective well-being (see below). At the same time, we also observe a positive correlation between our global measure of subjective well-being and the disposition towards the trading partner (Spearman's $\rho=.2388, p=.0434$ ), but not towards the third party (Spearman's $\rho=.1844, p=.1210$ ). This also offers an explanation for the observation in Section 3.2 that in NCC only the disposition towards the third party exhibits a signifcant decay but stays constant with regard to the trading partner. It seems important here that there is a single direct relationship such that the affective state can be unambiguously attributed towards a particular person. It, therefore, also 
seems not too surprising that we cannot find significant direct relations between the disposition towards a specific person and subjective well-being in CC where more people are involved and partnerships are much more unstable.

Table 10: Interaction success and well-being

\begin{tabular}{|c|c|c|c|c|}
\hline & \multicolumn{4}{|c|}{ Dependent variable: well-being } \\
\hline & \multirow{2}{*}{$\frac{\text { In NCC }}{\mathrm{A} / \mathrm{B}}$} & \multicolumn{3}{|c|}{ In $\mathrm{CC}$} \\
\hline & & $\mathrm{A}$ & B/C m.o. & B/C 1.o. \\
\hline Earnings & $0.2923^{* *}$ & 0.0184 & $0.0231^{* *}$ & -0.0089 \\
\hline per round & $(0.000)$ & $(0.053)$ & $(0.001)$ & $(0.638)$ \\
\hline \# of & & & & 0.1591 \\
\hline plays & & & & $(0.077)$ \\
\hline \multirow[t]{2}{*}{ Constant } & -0.9711 & 3.2342 & 1.1019 & 3.4360 \\
\hline & $(0.452)$ & $(0.170)$ & $(0.443)$ & $(0.088)$ \\
\hline adj. $R^{2}$ & 0.49 & 0.11 & 0.32 & 0.07 \\
\hline$N$ & 36 & 27 & 27 & 27 \\
\hline
\end{tabular}

Finally, we look at the relation between earnings in the interactive phase and our global measure of subjective well-being. Table 10 shows regressions with our global measure of subjective well-being as the dependent variable and interaction success, captured by earnings per round (and number of plays), as the independent variable. Here we find a significantly positive impact of earnings both for players in the NCC as well as for the more often chosen B/C players, and a marginally significantly positive effect for the A players. For the less often chosen B/C players well-being and earnings are unrelated. For them the number of plays has a marginally positive influence on well-being. These observations are summarized in the following regularity.

\section{Regularity 8}

A. Interaction success does positively affect NCC players' subjective well-being.

$B$. Interaction success does not affect the A players' subjective well-being significantly. C. Interaction success does positively affect the subjective well-being of the more often chosen B/C players, but does not affect the subjective well-being of less often chosen $B / C$ players. 
Importantly, as for social well-being, factors other than pure monetary gains play a significant role in the experienced subjective well-being of people. Competition by itself and the role people are immersed in in the competitive situations are important separate determinants of social and subjective well-being .

\section{Final Comments}

We find that competition matters, but in a different way than is typically assumed in economics. In our set-up with incomplete contracts competition has hidden costs that are related to the lack of control and the possibility of exclusion from trade. We observe that competition does neither have the expected allocative effects of increasing material efficiency nor does it help the short side of the market in terms of earnings. It has, however, positive effects on the subjective (experienced) well-being of people on the short side of the market. Importantly, at the same time competition has strong adverse effects on the social well-being of those who are on the long side of the market. Their experience with competition decreases their willingness to help others. This effect is strongest for those who are frequently excluded from trading. Additionally, being exposed to the competitive environment lowers subjective well-being and triggers negative emotions for those on the long side of the market. These effects can not be explained by interaction success and earnings alone. On balance, competition does not show up as very a positive force in our experiment.

One might speculate about potential longer term effects of our findings. Competition has substantially deteriorated the social relations between market participants and considerably depressed the subjective well-being of those on the long side of the market who are often excluded from the interaction. These facts might lead to the obstruction of future cooperation. Note, that the formation of mostly stable bilateral relations can not completely solve this problem. In a situation with competition, bilateral relations necessarily imply the exclusion of some parties from materially beneficial interactions. Additionally, in a dynamic society established bilateral relations will not hold forever. When new interactions between partners have to take place, they may bring together parties with a low level of social well-being. In addition, the subjective well-being of those parties that have previously been frequently excluded from the interaction may be low. All this does not seem a promising basis for a fruitful collaboration. 
In a more general sense, our evidence is in favor of the view that socio-psychological influences and those aspects of human interaction mostly related to material welfare and pecuniary incentives can (and should) not always be kept apart or disentangled. Granovetter (1985) refers to this as the embeddedness of economic activity in social relations. Continued interaction under competition affects the disposition towards others which, in turn, may feed back into future exchange relations. The interpersonal rivalry implied by competition can be seen to hurt the social relations which are necessary for the succesful pursuit of material wealth. Our results add to but are different from the criticism of market economies put forward by Lane (1991 and 2000). His point is, in essence, that in market economies people are drawn into striving too much for material things at the expense of companionship. Our contribution consists in providing evidence of the social and affective costs of competition as such.

Note that it would have been difficult to carry out our kind of analysis on the basis of field data alone, since in natural environments it would be impossible to find adequate data with the desired variation in competitive conditions. It probably would have been even harder to obtain controlled information about social value orientation and feelings which, in addition, would also have had to be connected to competition. In contrast, experiments make it possible to generate this kind of evidence in a systematic manner. 


\section{References}

Barrett-Howard, Edith and Tom R. Tyler (1986), "Procedural Justice as a Criterion in Allocation Decisions", Journal of Personality and Social Psychology, 50, 296-304.

Benoit, Jean-Pierre and Vijay Krishna (1985), "Finitely repeated games", Econometrica, 53, 890-904.

Bies, Robert, Thomas Tripp, and Margaret Neale (1993), "Procedural Fairness and Profit Seeking: The Perceived Legitimacy of Market Exploitation", Journal of Behavioral Decision Making, 6, 243-256.

Bolton, Gary, Jordi Brandts and Axel Ockenfels (2001), "Fair Procedures. Evidence from Games Involving Lotteries", mimeo, Institut d'Anàlisi Econòmica, Barcelona.

Bolton, Gary and Axel Ockenfels (2000), "ERC: A Theory of Equity, Reciprocity, and Competition", American Economic Review, 90, 166-193.

Bosman, Ronald and Frans van Winden (2002), "Emotional hazard in a power-to-take game experiment", The Economic Journal, 112, 147-169.

Bowles, Samuel (1998), "Endogenous Preferences: The Cultural Consequences of Markets and other Economic Institutions", Journal of Economic Literature, 36, 75111.

Brandts, Jordi and Gary Charness (2003), "Truth or Consequences: An Experiment", Management Science, 49, 116-130.

Brandts, Jordi and Gary Charness (2004), "Do Labor Market Conditions Affect Gift Exchange? Some Experimental Evidence", The Economic Journal, forthcoming, July 2004 .

Brandts, Jordi, Werner Güth and Andreas Stiehler (2002), "I want YOU. An experiment studying the selection effect when assigning distributive power", mimeo, Institut d'Anàlisi Econòmica (CSIC).

Brown, Martin, Armin Falk and Ernst Fehr (2003), "Contractual Incompleteness and the Nature of Market Interactions", Econometrica, forthcoming. 
Charness, Gary and David Levine (2000), "When are layoffs acceptable? Evidence from a quasi-experiment", Industrial Labor Relations Review, 53, 381-400.

Charness, Gary and Matthew Rabin (2002), "Understanding Social Preferences with Simple Tests", Quarterly Journal of Economics, 117, 817-869.

Davis, Douglas and Charles Holt (1994), "Equilibrium Cooperation in Three-Person Choice-of-Partner Games", Games and Economic Behavior, 7, 39-53.

van Dijk, Frans, Joep Sonnemans and Frans van Winden (2002), "Social Ties in a Public Goods Experiment", Journal of Public Economics, 85, 275-299.

Dufwenberg, Martin and Georg Kirchsteiger (2004), "A Theory of Sequential Reciprocity", Games and Economic Behavior, 47, 268-298.

Elster, Jon (1998), "Emotions and Economic Theory", The Economic Journal, 36, 2, 47-74.

Falk, Armin and Urs Fischbacher (1998," A Theory of Reciprocity", mimeo, University of Zurich.

Fehr, Ernst and Armin Falk (1999), "Wage Rigidity in a Competitive Incomplete Contract Market", Journal of Political Economy, 107, 106-134.

Fehr, Ernst, Georg Kirchsteiger and Arno Riedl (1993), "Does Fairness Prevent Market Clearing? An Experimental Investigation", Quarterly Journal of Economics, 108, $2,437-460$.

Fehr, Ernst, Georg Kirchsteiger and Arno Riedl (1998), "Gift Exchange and Reciprocity in Competitive Experimental Markets", European Economic Review, 42, $1-34$.

Fehr, Ernst and Klaus Schmidt (1999), "A Theory of Fairness, Competition, and Cooperation", Quarterly Journal of Economics, 114, 817-868.

Fraysse, J. and Michel Moreau (1985), "Collusive equilibria in oligopolies with long but finite lives", European Economic Review, 27, 45-55.

Friedman, James (1985), "Cooperative equilibria in finite horizon noncooperative supergames", Journal of Economic Theory, 35, 390-398. 
Frey, Bruno, Matthias Benz and Alois Stutzer (2002), "Introducing Procedural Utility: Not only What, but also How Matters", Journal of Institutional and Theoretical Economics, forthcoming.

Frey, Bruno and Alois Stutzer (2002), "What Economists Can Learn from Happiness Research", Journal of Economic Literature, vol. XL, 402-435.

Granovetter, Mark (1985), "Economic Action and Social Structure: The Problem of Embeddedness", American Journal of Sociology, 91, 481-510.

Güth, Werner, Nadege Marchand and Jean-Louis Rulliere (forthcoming), "On the Reliability of Reciprocal Fairness - An Experimental Study", Eastern Economic Review.

Hannan, R. Lynn, John Kagel and Donald Moser (2002), "Partial Gift Exchange in Experimental Labor Markets: Impact of Subject Population Differences, Productivity Differences and Effort Request on Behavior", Journal of Labor Economics, 20, 923-951.

Kahneman, Daniel, Ed Diener and Norbert Schwartz (Eds.) (1999), Well-Being. The Foundations of Hedonic Psychology, Russell Sage Foundation, New York.

Kahnemann, Daniel, Jack Knetsch, and Richard Thaler (1986), "Fairness as a Constraint on Profit-Seeking: Entitlements in the Market", American Economic Review, 76, 728-741.

Kollock, Peter (1994), "The Emergence of Exchange Structures: An Experimental Study of Uncertainty, Commitment and Trust", American Journal of Sociology, 100, 313-345.

Kreps, David, Paul Milgrom, John Roberts and Robert Wilson (1982), "Rational cooperation in the finitely repeated prisoner's dilemma", Journal of Economic Theory, 27, 245-252.

Lane, Robert F. (1991), The Market Experience, Cambridge Univesity Press, Cambridge.

Lane, Robert F. (2000), The Loss of Happiness in Market Democracies, Yale University Press, New Haven and London. 
Lang, Peter J. (1980), "Behavioral treatment and bio-behavioral assessments: computer applications", in Sidowsky, J. B., Johnson, J. H. and T. A. Williams (eds.), Technology in Mental Health Care Delivery Systems, NJ Ablex, Norwood.

Lawler, Edward, Jeongkoo Yoon, Mouraine Baker and Michael Large (1995), "Mutual Dependence and Gift Giving in Exchange Relations", Advances in Group Processes, 12, 271-298.

Lawler, Edward and Shane Thye (1999), "Bringing Emotions into Social Exchange Theory", Annual Reiew of Sociology, 25, 217-244.

Liebrand, Wim (1984), "The effect of social motives, communication and group sizes on behaviour in an n-person multi-stage mixed motive game", European Journal of Social Psychology, 14, 239-264.

Lind, Allan and Tom R. Tyler (1988), The Social Psychology of Procedural Justice, New York: Plenum Press.

Loewenstein, George (2000), "Emotions in Economic Theory and Economic Behavior", American Economic Review, Papers and Proceedings, 90, 426-432.

Nydegger, Rudy and Houston Owen (1975), "Two-Person Bargaining: An Experimental Test of the Nash Axioms", International Journal of Game Theory, 3239-249.

Offerman, Theo, Joep Sonnemans and Arthur Schram (1996), "Value Orientation, Expectations and Voluntary Contributions in Public Goods", The Economic Journal, 106, 817-845.

Roth, Alvin, Vesna Prasnikar, Masahiro Okuwo-Fujiwara, and Shmuel Zamir (1991), "Bargaining and market behavior in Jerusalem, Ljubiljana, Pittsburgh and Tokyo: an experimental study", American Economic Review, 81, 1068-1095.

Selten, Reinhard (1967), "Die Strategiemethode zur Erforschung des Eingeschränkt Rationalen Verhaltens im Rahmen eines Oligopolexperiments", in Beiträge zur Experimentellen Wirtschaftsforschung, H. Sauermann, ed., 136-168.

Shapiro, Carl and Joseph Stiglitz (1984), "Equilibrium Unemployment as a Worker Discipline Device", American Economic Review, 74, 433-444. 
Sonnemans, Joep (1991), "Structure and Determinants of Emotional Intensity", Ph. D.-thesis, University of Amsterdam.

Sonnemans, Joep, Frans van Dijk and Frans van Winden (2001), "On the Dynamics of Social Ties Structures in Groups", mimeo, CREED, Universiteit van Amsterdam. Stigler, George (1987), in The New Palgrave. A Dictionary of Economics, J. Eatwell, M. Milgate and P. Newman, eds., The MacMillan Press Limited, London, 531535 . 